LIZA MARGARETH MEDEIROS DE CARVALHO SOUSA

Hipóxia e luteólise em cadelas não prenhes 


\section{Hipóxia e luteólise em cadelas não prenhes}

Tese apresentada ao Programa de Pós-Graduação em Anatomia dos Animais Domésticos e Silvestres da Faculdade de Medicina Veterinária e Zootecnia da Universidade de São Paulo para obtenção do título de Doutor em Ciências

Departamento:

Cirurgia

Área de Concentração:

Anatomia dos Animais Domésticos e Silvestres

Orientadora:

Profa. Dra. Paula de Carvalho Papa

Coorientador:

Prof. Dr. Mariusz Pawel Kowalewski 
Autorizo a reprodução parcial ou total desta obra, para fins acadêmicos, desde que citada a fonte.

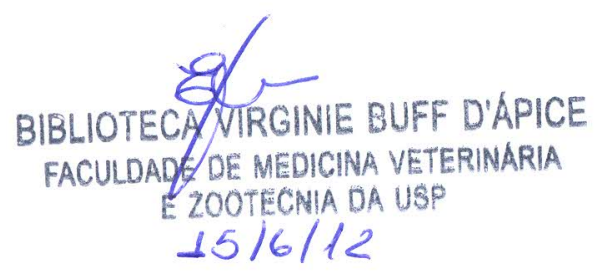

DADOS INTERNACIONAIS DE CATALOGAÇÃO-NA-PUBLICAÇÃO

(Biblioteca Virginie Buff D’Ápice da Faculdade de Medicina Veterinária e Zootecnia da Universidade de São Paulo)

Sousa, Liza Margareth Medeiros de Carvalho

Hipóxia e luteólise em cadelas não prenhes / Liza Margareth Medeiros de Carvalho Sousa. -- 2012.

83 f. : il.

Tese (Doutorado) - Universidade de São Paulo. Faculdade de Medicina Veterinária e Zootecnia. Departamento de Cirurgia, São Paulo, 2012.

Programa de Pós-Graduação: Anatomia dos Animais Domésticos e Silvestres. Área de concentração: Anatomia dos Animais Domésticos e Silvestres.

Orientador: Prof. Dr. Mariusz Pawel Kowalewski.

1. HIF1A. 2. Sistema VEGF. 3. GLUTs. 4. Corpo lúteo. 5. Diestro. I. Título. 


\section{ERRATA}

SOUSA, L. M. M. C. Hipóxia e luteólise em cadelas não prenhes. 2012. 80 f. Tese (Doutorado em Ciências) Faculdade de Medicina Veterinária e Zootecnia, Universidade de São Paulo, São Paulo, 2012.
Página
Resumo
Parágrafo
1음
Onde se lê
$80 \mathrm{f}$.
Leia-se
$83 \mathrm{f}$. 
Certificamos que o Projeto intitulado "Hipóxia e luteólise em cadelas não prenhes", protocolado sob o n\% $1432 / 2008$, utilizando 28 (vinte e oito) câes, sob a responsabilidade da Profa. Dra. Paula de Carvalho Papa, está de acordo com os principios éticos de experimentação animal da Comissão de Bioética da Faculdade de Medicina Veterinária e Zootecnia da Universidade de Săo Paulo e foi aprovado "ad referendum".

We certify that the Research "Hypoxia and luteoysis in non pregnant dogs", utilizing 28 (twenty eight) dogs, protocol number 1432/2008, under the responsibility Profa. Dra. Paula de Carvalho Papa, agree with Ethical Principles in Animal Research adopted by Bioethic Commission of the School of Veterinary Medicine and Animal Science of University of São Paulo and was approved "ad referendum" of the meeting.

Sào Paulo, 21 de agosto de 2008

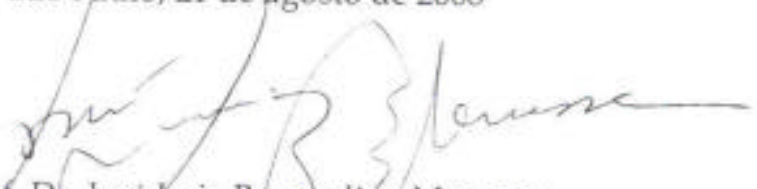

Prof, Dr. Jose Luiz Bernardino Merusse

Presidente da Comissâa de Bioética

FMVZ/USP 


\section{FOLHA DE AVALIAÇÃO}

Nome: SOUSA, Liza Margareth Medeiros de Carvalho

Título: Hipóxia e luteólise em cadelas não prenhes

Tese apresentada ao Programa de Pós-Graduação em Anatomia dos Animais Domésticos e Silvestres da Faculdade de Medicina Veterinária e Zootecnia da Universidade de São Paulo para obtenção do título de Doutor em Ciências

Data____

Banca Examinadora

Prof. Dr.

Instituição: Julgamento:

Prof. Dr.

Instituição: Julgamento:

Prof. Dr.

Instituição: Julgamento:

Prof. Dr.

Instituição: Julgamento:

Prof. Dr.

Instituição: Julgamento:

Prof. Dr.

Instituição:: Julgamento: 
"Por mais árdua queseja a luta, por mais distantequeum ideal seapresente, por mais difícil queseja a caminhada, existesempreuma manera devencer: a Perseverança."

Autor desconhecido 


\section{DEDICATÓR IA}

A o meu esposoUiran, por sua existên da, por estar sempreao meu lado, pelo companheirismo, respeito eincentivo, pela paciência esabedoria para transmitir seu conhecimento e experiência, sempre presenteem minha vida, com amor ecarinho, dedico essetrabalho

À minha filha Thaís, pela oportunidade deexperimentar a mais pura forma deamor, revelando-mea certeza dequetodos os dias, ao seu lado, são maravil hosos

A os meus pais, Joãoe Maria Elizabeth, quepor uma vida de dedicação, amor etrabal ho sempre possibilitaram às suas filhas a oportunidadedereal izar son hos econquistas.

À minha irmã Juliana, quepela dedicação eamor possi bilitou a realização dessa etapa tão importantedeminha vida 


\section{AGRADECIMENTO ES PECIAL}

À minha orientadora, profa. Paula deCarvalhoPapa, por ser minha guia, responsável direta pela missão queagora secumpre As indicações, as dicas, as correções, as oportunidades eatémesmo al guns contratempos quepassaram por essa relação

orientadora eorientanda. Tudo isso compôs uma somatória fundamental não só para a construção do pensamento, mas também para a maturidadedetoda uma vida.

Muitoobrigada! 


\section{AGRADECIMENTOS}

À Faculdade de Medicina Veterinária e Z ootecnia da Universidade de São Paulo, pela infraestrutura dequalidade para o desenvolviemnto prof issional adequado

Aos professores Dra. Maria Angéica Miglino, Dr José Roberto Kfoury Jr., Dr Francisco Javier Hernandez-Blazquez, por terem disponibilizado seus laboratórios imprescindívés para a execução dos experimentos

Ao prof Mariusz Kowalewski, pelas dicas e conselhos que mudaram os rumos desse trabalho

À Luciana Alves de Fátima, um agradecimento especial, pela amizade, pela companhia durantetodos esses anos, pela dedicação e carinho, pela ajuda mais quefundamental nos momentos mais difíces. Lú, muito obrigada!

Aos caros amigos de laboratórioA lex Machado, Renata S antos S ilva, Vanessa Uemura da Fonseca, Valdir PavaneloJr., Giuliano L esnau, Nathia Rigoglio, Juliana Ferrão eAntenor Bonfim quefizeram efazem partedessa conquista

Aos alunos deIniciação Científica, Garros Fontinhas, FelipeJusceleejaquelineYakk o pda convivência duranteesse período

Aos professores do Departamento de Patologia, Dra Maria Lúcia Z aidan Dagli e Bruno Cogliati por permitir a real ização de partedo experimento em seus laboratórios

À Dra Ivana Carvalho e às ONGs CEPRA e Vira lata é dez por permitir a coleta de materiais em seus muti rões decastração, imprescin díveis para a real ização dessetrabal ho

Aos proprietários que disponibilizaram seus animais de estimação, os quais foram in dispen sáves para o desenvol vimento dessa pesquisa 
Ao R afael ea Carolina, por disponibilizarem o seu tempo ea sua habilidade na realização das cirurgias

Ao prof GuilhermedePádua Nogueira ea Devani, por disponibilizar o seu laboratório epelo auxílio nas dosagens hormonais

À FAPES P, pelofinanciamento desseprojeto

A todos queparticiparam direta ou indiretamentena realização dessetrabal ho 


\section{RESUMO}

SOUSA, L. M. M. C. Hipóxia e luteólise em cadelas não prenhes. [Hypoxia and luteolysis in non pregnant dogs]. 2012. 80 f. Tese (Doutorado em Ciências) - Faculdade de Medicina Veterinária e Zootecnia, Universidade de São Paulo, São Paulo, 2012.

Com o intuito de investigar se a hipóxia representa um dos desencadeadores da regressão luteínica em cadelas não prenhes, o presente estudo foi delineado para analisar a expressão do fator transcricional indutível por hipóxia HIF1A e a de seus genes-alvo relacionados à angiogênese, como o fator de crescimento endotelial vascular (VEGFA) e à captação de glicose, como as proteínas transportadoras facilitadoras GLUT1/SLC2A1 e GLUT4/SLC2A4 no corpo lúteo canino ao longo do diestro (dias 10 a 70 após a ovulação). Para tal, utilizou-se imuno-histoquímica e western blotting para localizar e quantificar as proteínas do HIF1A, GLUT1 e GLUT4 e PCR em tempo real para quantificar a expressão do RNAm de HIF1A, SLC2A1, SLC2A4, VEGFA, FLT1 e KDR. Além disso, células luteínicas nas fases inicial (dia 10), média (dia 30) e final (dia 60) foram submetidas ao tratamento com cloreto de cobalto (CoCl2) a $500 \mu \mathrm{M}$ para avaliar os efeitos da hipóxia sobre a expressão gênica dos fatores acima citados, bem como sobre a produção de progesterona e 17ß-estradiol. Nossos resultados demonstraram que o HIF1A é expresso pelo corpo lúteo canino de maneira tempo-dependente ao longo do diestro, e que a expressão de seu RNAm está diretamente correlacionada a expressão gênica de $S L C 2 A 1, S L C 2 A 4, V E G F A, F L T 1$ e $K D R$ e com as concentrações de progesterona periférica. No cultivo primário de células luteínicas, a hipóxia induzida pelo $\mathrm{CoCl} 2$ diminuiu a produção de progesterona e de $17 ß$-estradiol e estimulou significativamente a expressão de HIF1A, SLC2A1, SLC2A4 e VEGFA. Esses resultados sugerem que o HIF1A constitui um dos fatores regulatórios da função do corpo lúteo canino participando da modulação de processos como esteroidogêne, angiogênese e da captação de glicose, atuando como fator luteolítico.

Palavras-chave: HIF1A. Sistema VEGF. GLUTs. Corpo lúteo. Diestro. 


\begin{abstract}
SOUSA, L. M. M. C. Hypoxia and luteolysis in non pregnant dogs. [Hipóxia e luteólise em cadelas não prenhes]. 2012. 80 f. Tese (Doutorado em Ciências) - Faculdade de Medicina Veterinária e Zootecnia, Universidade de São Paulo, São Paulo, 2012.

This study was designed to investigate if hypoxia is one of the triggers of luteal regression in non-pregnant bitches. For that, we analyzed the hypoxia-inducible factor (HIF1A) expression as well as the expression of its target genes related to angiogenesis (vascular endothelial growth factor - VEGFA) and to glucose uptake (glucose transporters - GLUT/SLC2A 1 and 4) in canine corpus luteum throughout diestrus (days 10 to 70 after ovulation). We used immunohistochemistry and western blotting to localize and quantify the protein expression of HIF1A, GLUT1 and GLUT4, respectively, and real time PCR to analyze HIF1A, SLC2A1, $S L C 2 A 4, V E G F A, F L T 1$ and KDR gene expression. Moreover, luteal cells from early (day 10), mid (day 30) and late luteal phase (day 60) were submitted to $500 \mu \mathrm{M}$ cobalt chloride $(\mathrm{CoCl} 2)$ treatment to verify hypoxia effects on gene expression of the above cited genes and on progesterone and 17ß-estradiol production. Our results showed that luteal cells expressed HIF1A in a time-dependent manner over diestrus and that its expression was directly correlated to both SLC2A1, SLC2A4, VEGFA, FLT1 and KDR gene expression and progesterone production. The protein expression of the studied genes also changed over diestrus and was correlated with the respective gene expression. In primary luteal cells culture, cobalt chloride-induced hypoxia downregulated progesterone and 17ß-estradiol production, but upregulated $H I F 1 A, S L C 2 A 1, S L C 2 A 4$ and VEGFA gene expression. These findings suggest that HIF1A is one of the factors regulating canine luteal function by modulating important process as steroidogenesis, angiogenesis and glucose uptake, acting as a pro-survival factor.
\end{abstract}

Keywords: HIF1A. VEGF system. GLUTs. Corpus luteum. Diestrus. 


\section{LISTA DE FIGURAS}

Figura 1 - Efeito das concentrações crescentes de $\operatorname{CoCl} 2(0-1000 \mu \mathrm{M})$ na expressão do HIF1A em células luteínicas caninas oriundas do dia 10 após a ovulação. A expressão protéica e gênica foi determinada por western blotting e PCR em tempo real, respectivamente, após 24 horas do início do tratamento. As proteínas totais isoladas de homogenatos de tecido luteínico foram detectadas com anticorpos específicos e normalizados com a expressão de ACTB, enquanto as quantificações relativas da expressão do RNAm do HIF IA foram normalizadas com a expressão da ciclofilina A como controle endógeno. Os dados são expressos como média \pm DP. Barras com letras diferentes: $\mathrm{p}<0,05$.

Figura 2 - Concentrações séricas de progesterona (ng/ml; A) e 17ß-estradiol (pg/ml; B) em cadelas ao longo do diestro (dias 10 - 70 após a ovulação). Dados representados por média \pm desvio padrão ( $n=3-4$ animais/grupo). Asteriscos indicam diferença significativa $(\mathrm{p}<0,05)$ em relação aos demais dias observados . .46

Figura 3 - Concentrações séricas de glicose (mg/dl; A) e insulina $(\mu \mathrm{U} / \mathrm{ml}$; B) em cadelas ao longo do diestro (dias $10-70$ após a ovulação). Dados representados por média \pm desvio padrão $(\mathrm{n}=3-4$ animais/grupo). Asteriscos indicam diferença significativa $(\mathrm{p}<0,05)$ em relação aos demais dias observados

Figura 4 - Imunolocalização do HIF1A no corpo lúteo canino ao longo do diestro. (A e B) Dias 10 e 20: a proteína HIF1A é detectada no citoplasma (coloração marrom) de células luteínicas, endoteliais e estromais. (C) Dia 30: o HIF é observado tanto no citoplasma quanto no núcleo das células luteínicas (setas brancas). (D e E) Dias 40 e 50: nesse período, a intensidade da reação tanto no núcleo qua nto no citoplasma encontra-se reduzida. ( $F$ e G) Dias 60 e 70: observa-se intensa reação nuclear e citoplasmática. (H) Placenta humana: controle positivo. (I) Dia 20: controle negativo. Barras $=20 \mu \mathrm{m}$

Figura 5 - Imunolocalização de GLUT1 no corpo lúteo canino ao longo do diestro. (A, B e C) Dias 10, 20 e 30: observa-se intensa reação no meio intracelular (coloração marrom) de células luteínicas, endoteliais e estromais. (D, E, F e G) Dias 40, 50, 60 e 70: a intensidade da reação diminui à medida que o diestro avança. $(\mathrm{H})$ Placenta humana: controle positivo. (I) Dia 20: controle negativo. Barras $=20 \mu \mathrm{m}$

Figura 6 - Imunolocalização de GLUT4 no corpo lúteo canino ao longo do diestro. (A, B e C) Dias 10, 20 e 30: observa-se intensa reação no meio intracelular (coloração marrom) de células luteínicas, endoteliais e estromais. (D, E, F e G) Dias 40, 50, 60 e 70: a intensidade da reação diminui à medida que o diestro avança. $(\mathrm{H})$ Músculo esquelético de camundongo: controle positivo. (I) Dia 20: controle negativo. Barras $=20 \mu \mathrm{m}$

Figura 7 - Expressão protéica de $\operatorname{HIF} 1 \mathrm{~A}$ (A, B) no corpo lúteo canino ao longo do diestro. As imagens de eletroforese representam três experimentos independentes. As proteínas totais isoladas de homogenatos de tecido luteínico foram detectadas com 
anticorpo específico e normalizadas com a expressão de actina,beta (ACTB). Os dados são apresentados como média \pm DP. Barras com letras diferentes: $p<0,05$

Figura 8 - Expressão protéica de GLUT1 (A e B) e GLUT4 (C e D) no corpo lúteo canino ao longo do diestro. As imagens de eletroforese representam três experimentos independentes. As proteínas totais isoladas de homogenatos de tecido luteínico foram detectadas com anticorpos específicos e normalizadas com a expressão de actina,beta (ACTB). Os dados são apresentados como média \pm DP. Barras com letras diferentes: $\mathrm{p}<0,05$. .53

Figura 9 - Expressão gênica de $H I F 1 A$ (A), SLC2Al (B), SLC2A4 (C), VEGFA (D), FLT1 (E) e $K D R(\mathrm{~F})$ no corpo lúteo de cadelas ao longo do diestro (dias 10 a 70 após a ovulação). Dados representados por média \pm desvio padrão da expressão relativa do gene ( $\mathrm{n}=3-4$ animais/grupo). Barras com letras e asteriscos indicam diferença significativa $(\mathrm{p}<0,05)$

Figura 10 - Cultivo primário de células luteínicas de cadelas. (A) Células em processo de adesão à placa de petri após 12 - 24 h. (B) Agrupamento de células luteínicas formados após $48-72 \mathrm{~h}$ de cultivo. (C) Monocamada celular confluente de células luteínicas após $5-7$ dias. Barra $=50 \mu \mathrm{m}$. (D) Fotomicrografia de células luteínicas caninas demonstrando o formato poligonal característico, grânulos e vacúolos de lipídeos (a) e núcleo (b). Barra $=20 \mu \mathrm{m}$. 58

Figura 11 - Efeito da hipóxia (induzida por $\mathrm{CoCl} 2$ a $500 \mu \mathrm{M}$ ) na produção de progesterona (ng/ml; A) e de $17 ß$-estradiol (pg/ml; B) em células luteínicas ( $=3$ animais / grupo). Os dados foram representados por média \pm desvio padrão. Asteriscos representam diferença significativa $(\mathrm{p}<0,05)$

Figura 12 - Efeito da hipóxia (induzida por $\mathrm{CoCl} 2$ a $500 \mu \mathrm{M}$ ) na expressão gênica de HIF1A (A), SLC2A4 (B), SLC2A1 (C) e VEGFA (D) em células luteínicas nos dias 10, 30 e 60 após a ovulação ( $\mathrm{n}=3$ animais / grupo). Os dados foram transformados em raiz quadrada e representados por média \pm desvio padrão. Asteriscos representam diferença significativa $(\mathrm{p}<0,05)$ 


\section{LISTA DE TABELAS}

Tabela 1 - Média e desvio padrão dos valores obtidos para os índices de relação insulina:glicose, relação insulina:glicose corrigida, HOMA2 e HOMA em cadelas ao longo do diestro ...................................................................... 47

Tabela 2 - Coeficientes de correlação entre a expressão de HIF1A, SLC2A1, SLC2A4 e sistema VEGF e a produção de progesterona e 17ß-estradiol no corpo lúteo

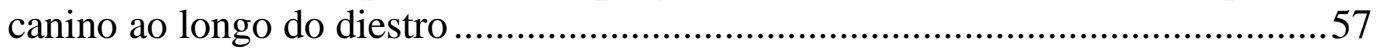




\section{LISTA DE QUADROS}

Quadro 1 - Anticorpos primários utilizados nas técnicas de imuno-histoquímica e western

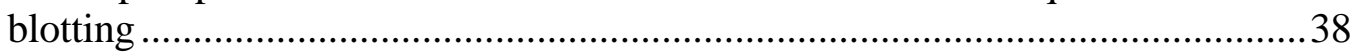

Quadro 2 - Primers e sondas utilizados no PCR em tempo real...........................................41 


\section{LISTA DE ABREVIATURAS}

$\mu \mathrm{g}$ - micrograma

$\mu \mathrm{l}$ - microlitro

$\mu \mathrm{m}$ - micrometro

ACTB - beta, actina

ACTH- hormônio adrenocorticotrófico

Akt - proteína quinase B

ANOVA - análise de variância

BSA - Albumina sérica bovina

${ }^{\circ} \mathrm{C}$ - graus Celsius

CD8 - cluster de diferenciação 8

cDNA - ácido desoxirribonucleico complementar

CL - corpo lúteo

cm - centímetro

$\mathrm{CO}$ - hemoxigenase 1

$\mathrm{CO}_{2}$ - dióxido de carbono

$\mathrm{CoCl} 2$ - cloreto de cobalto

COX1 - Ciclo-oxigenase-1

COX2 - Ciclo-oxigenase- 2

CY11A1/ P450scc - citocromo P450

DMEM - Dulbeco's Modified Eagle Medium

DNA - ácido desoxirribonucleico

DNAse - enzima que degrada o ácido desoxirribonucleico

dNTP - desorribonuleotídeo trifosfatado

DTT - Dithiothreitol

$\mathrm{E}_{2}$ - estrógenos

ECL - Enhanced Chemiluminescence

EDTA - ácido etilenodiamino tetra-acético

ESR1 - receptor de estrógenos 1

FLT1 - like-tyrosine kinase receptor 1

FSH - hormônio folículo estimulante

$g$ - força $g$ 
GH - hormônio de crescimento

GH - hormônio do crescimento

GLUT - transportador de glicose

$\mathrm{H}$ - hora

$\mathrm{H}_{2} \mathrm{O}$ - água

HEPES - N-[2-hidroxietil] piperazina - [2-ácido etanosulfônico]

HIF1A - fator indutível por hipóxia

HOMA - Modelo de Avaliação da Homeostase

HR - insulinemia x glicemia

HREs - elementos responsivos à hipóxia

HRP - peroxidase

HSD3B - hidroxiesteróide-dehidrogenase 3B

IGF-I - fator de crescimento semelhante à insulina

IgG - imunoglobulina $\mathrm{G}$

IkBs - regulador de inibição kappa B

IRS - substrato do receptor de insulina

$\mathrm{KCl}$ - cloreto de potássio

$\mathrm{kDa}$ - kilodaltons

KDR - kinase insert domain receptor

$\mathrm{Kg}$ - quilograma

$\mathrm{KH}_{2} \mathrm{PO}_{4}$ - fosfato de potássio monobásico

LH - hormônio luteinizante

LSAB - streptoavidina-biotina-peroxidase

M - molar

MEF - transportadores de membrana

$\mu \mathrm{g}$ - micrograma

MHC-II - complexo principal de histocompatibilidade calse II

$\mathrm{ml}$ - mililitro

$\mathrm{mM}$ - milimolar

$\mathrm{Na}_{2} \mathrm{HPO}_{4}$ - fosfato de sódio dibásico

$\mathrm{NaCl}$ - cloreto de sódio

ng - nanograma

$\mathrm{nM}$ - nanomolar

NOS - óxido nítrico sintetase 
ODDD - domínio de degradação oxigênio-dependente

OSH - ovariosalpingohisterectomia

P.M. - peso molecular

P4 - progesterona

P5 - pregnenolona

PBS - solução tampão fosfato

PCR - reação em cadeia pela polimerase

pg - picograma

PGF - fator de crescimento placentário / prostaglandina

$\mathrm{pH}$ - potencial hidrogênio iônico

PKA - proteína quinase A

PPIA - ciclofilina A

PRKAA - AMP-proteína quinase ativada

RI:GC - insulina:glicose corrigida

RIA - radioimunoensaio

RNA - ácido ribonucleico

RNAm - ácido ribonucleico mensageiro

rpm - rotação por minuto

RT - transcrição reversa

SDS - dodecil sulfato de sódio

SLC2A 4 - transportador de soluto 2 membro 4

STAR - proteína esteroidogênica regulatória aguda

Tris-HCL - tris base cloreto de hidrogênio

TTBS - tampão base trifosfato com tween

UI - unidade internacional

VEGFA - fator de crescimento endotelial vascular

VHL - Von Hippel-Lindau 


\section{SUMÁRIO}

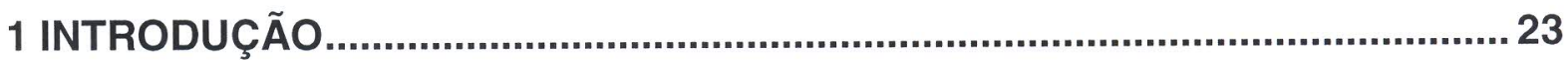

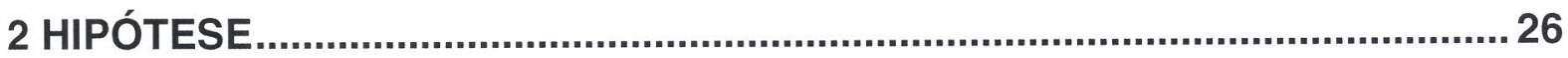

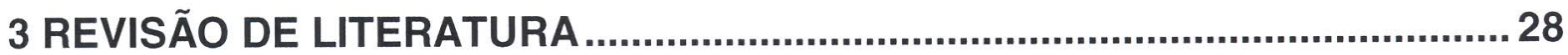

3.1 O CICLO REPRODUTIVO DAS CADELAS ................................................... 28

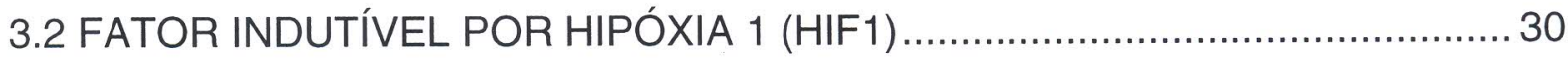

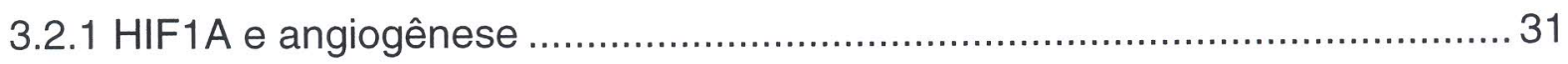

3.2.2 HIF1A e adaptação metabólica................................................................ 32

4 MATERIAL E MÉTODOS ............................................................................... 35

4.1 DETERMINAÇÃO DE PROGESTERONA, 17B-ESTRADIOL, INSULINA E

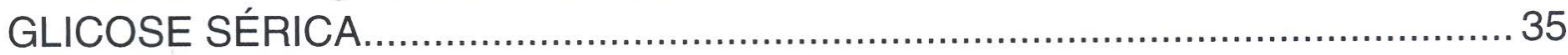

4.2 ESTIMATIVA DA SENSIBILIDADE INSULÍNICA........................................... 35

4.3 IMUNO-HISTOQUÍMICA PARA HIF1A, GLUT1 E GLUT4 ….......................... 36

4.4 WESTERN BLOTTING PARA HIF1A, GLUT1 E GLUT4 …............................ 37

4.5 EXPRESSÃO GÊNICA DE HIF1A, SLC2A1, SLC2A4, VEGFA, FLT1 E KDR NO CORPO LÚTEO CANINO …...................................................... 38

4.5.1 Transcrição reversa e síntese de cDNA ……….............................................. 39

4.6 ISOLAMENTO DAS CÉLULAS LUTEÍNICAS .............................................. 41

4.6.1 Efeito da hipóxia na função luteínica ......................................................... 41

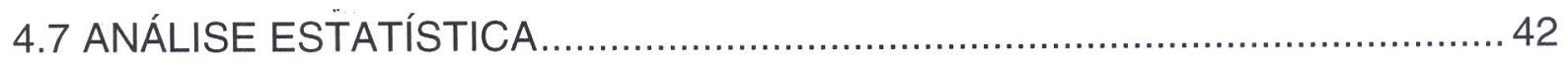

5 RESULTADOS ............................................................................................. 46

5.1 PERFIL SÉRICO DE PROGESTERONA E 17ß-ESTRADIOL.......................... 46

5.2 PERFIL SÉRICO DE GLICOSE, INSULINA E ÍNDICES DE

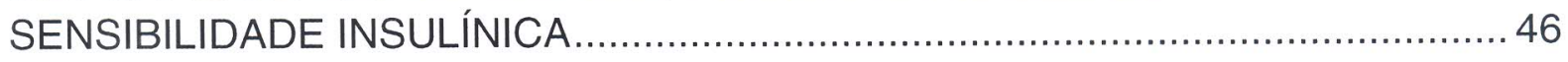

5.3 EXPRESSÃO ESPAÇO-TEMPORAL DE HIF1A, GLUT1 E GLUT4 NO CORPO LÚTEO CANINO AO LONGO DO DIESTRO.

5.4 EXPRESSÃO QUANTITATIVA DE HIF1A, GLUT1 E GLUT4 NO CORPO LÚTEO CANINO AO LONGO DO DIESTRO. 
5.5 EXPRESSÃO GÊNICA DE HIF1A, SLC2A1/GLUT1, SLC2A4/GLUT4, VEGFA, FLT1 E KDR NO CORPO LÚTEO CANINO AO LONGO DO DIESTRO .. 54 5.6 CORRELAÇÃO ENTRE A EXPRESSÃO PROTÉICA DE HIF1A, GLUT1 E GLUT4 E GÊNICA DE HIF1A, SLC2A1, SLC2A4, VEGFA, FLT1 E KDR E AS CONCENTRAÇÕES DE PROGESTERONA E 17ß-ESTRADIOL

5.7 CARACTERIZAÇÃO MORFOLÓGICA DAS CÉLULAS LUTEÍNICAS CANINAS 58

5.8 EFEITO DA HIPÓXIA NA EXPRESSÃO GÊNICA DE HIF1A, SLC2A1, SLC2A4 E VEGFA NAS CÉLULAS LUTEÍNICAS CANINAS

5.9 EFEITO DA HIPÓXIA NA PRODUÇÃO DE PROGESTERONA DAS CÉLULAS LUTEÍNICAS CANINAS.

6 DISCUSSÃO. 63

7 CONCLUSÃO 72 REFERÊNCIAS 
INTRO DUÇÃO 


\section{INTRODUÇÃO}

Em cadelas prenhes e não prenhes, o corpo lúteo é a principal fonte de progesterona. Diferentemente do que acontece em outras espécies domésticas, as concentrações de progesterona são similares em cadelas prenhes e não prenhes, exceto pelo fato de que na cadela prenhe ocorre um declínio abrupto da mesma antes do trabalho de parto, devido à ação da prostaglandina F2a de origem uterina, e na não prenhe, o declínio é gradual e lento por não existir um mecanismo luteolítico agudo (HOFFMANN et al., 1992). Os possíveis mecanismos desencadeadores da luteólise têm sido extensivamente investigados (HOFFMANN et al., 2004; KOWALEWSKI et al., 2006a; KOWALEWSKI et al., 2006b; PAPA; HOFFMANN, 2011) e a lenta regressão do CL parece tratar-se de um processo passivo degenerativo na ausência de uma luteólise ativa, relacionado, pelo menos em parte, a mecanismos de modulação autócrinos e parácrinos (KOWALEWSKI; MUTEMBEI; HOFFMANN, 2008).

O corpo lúteo consiste em uma glândula endócrina transitória que é submetida ao rápido crescimento e diferenciação celular e regressão controlada durante cada ciclo ovariano (DEVOTO et al., 2002). As concomitantes modificações nas condições metabólicas são dependentes do estabelecimento de uma rica rede vascular para proporcionar a adequada difusão de oxigênio e de nutrientes para o órgão, os quais são essenciais para a produção de progesterona. Características morfológicas de degeneração das células endoteliais e luteínicas em cadelas são observadas primeiramente após o dia 45 da ovulação, paralelamente a diminuição da produção de progesterona e do fluxo sanguíneo local (SONNACK, 2009). Consequentemente, as tensões de oxigênio tendem a diminuir, sugerindo que a presença de um ambiente hipóxico.

Conforme estudos prévios, a hipóxia pode estar envolvida na angiogênese e na esteroidogênese durante o desenvolvimento do corpo lúteo (KOGA et al., 2000; NISHIMURA; OKUDA, 2010), via indução de fatores transcricionais específicos, dentre eles o fator indutível por hipóxia ou HIF1A (SEMENZA, 2003), o qual atua na regulação de vários genes de modo a promover a homeostase de oxigênio celular, local e sistêmica. Dentre esses genes estão o fator de crescimento endotelial vascular (VEGFA), o qual é um importante fator angiogênico para a formação do corpo lúteo (SEMENZA, 2003; NISHIMURA; OKUDA, 2010) e genes relacionados à captação de glicose, pois como a glicose é o principal substrato energético para as atividades ovarianas (RABIEE et al., 1997) e trata-se de uma molécula hidrofílica, incapaz de atravessar a membrana plasmática, seu 
caminho através da membrana é feito via transportadores de glicose facultativos, GLUT1 a GLUT14 (THORENS; MUECKLER, 2010). Além do HIF1A, a expressão dos transportadores de glicose é regulada por fatores intraovarianos envolvidos no desenvolvimento folicular, maturação e ovulação, conforme descrito até o momento: estrógenos $\left(\mathrm{E}_{2}\right)$, fator de crescimento da insulina (IGF)-I e interleucina-1ß (KOL et al., 1997; ZHOU, J.; BIEVRE; BONDY, 2000), bem como as gonadotrofinas (KODAMAN; BEHRMAN, 1999), indicando que o ovário possui um mecanismo regulatório local para a captação de glicose e sobrevivência celular.

Todavia, se a expressão do sistema VEGFA e dos transportadores de glicose GLUT1 e GLUT4 é resultado ou causa do decréscimo da função luteínica nas cadelas ainda é desconhecido. Isto se aplica também ao papel da hipóxia no processo. Assim, o presente estudo foi delineado para investigar a expressão do HIF1A no corpo lúteo canino ao longo do diestro e as interações entre este e o sistema VEGFA e os transportadores de glicose. O efeito da hipóxia na esteroidogênese das células luteínicas também foi investigado, em uma tentativa de estabelecer os mecanismos subjacentes que regulam a dinâmica vascular e alterações metabólicas no CL canino, especialmente os que ocorrem durante a luteólise. 
HIPÓTESE 


\section{HIPÓTESE}

A hipótese do presente estudo é a de que a hipóxia, via fator indutível por hipóxia (HIF1A), está envolvida em processos importantes como a angiogênese e a disponibilidade de glicose através da regulação de fatores angiogênicos como o fator de crescimento endotelial vascular (VEGF) e de proteínas transportadoras de glicose (GLUTs) influenciando, dessa forma, a função do corpo lúteo durante o diestro. Para testar tal hipótese, o presente estudo foi delineado para obter maiores informações sobre a expressão do HIF1A e de seus alvos sistema VEGF e transportadores de glicose GLUT1 e GLUT4 - no corpo lúteo canino. Assim, os seguintes objetivos foram estabelecidos:

- Determinar os perfis de progesterona, 17ß-estradiol e insulina por radioimunoensaio (RIE) e de glicose por ensaio enzimático colorimétrico;

- Analisar a distribuição tecidual e a expressão protéica de HIF1 A, GLUT1 e GLUT4 ao longo do diestro (dias 10, 20, 30, 40, 50, 60 e 70 após a ovulação) por imunohistoquímica e western blotting, respectivamente;

- Analisar a expressão gênica de HIF1A, SLC2A1/GLUT1,SLC2A4/GLUT4, VEGFA, FLT1 e KDR ao longo do diestro (dias 10, 20, 30, 40, 50, 60 e 70 após a ovulação) por PCR em tempo real.

- Isolar e cultivar células luteínicas nos dias 10, 30 e 60 após a ovulação sob condições normóxicas e hipóxicas (na ausência ou presença de cloreto de cobalto - $\mathrm{COCl}_{2}$ a 500 $\mu \mathrm{M})$.

- Analisar os efeitos da hipóxia sobre a expressão gênica de HIF1A, SLC2A1, SLC2A4, VEGFA, FLT1 e KDR após 24 horas de tratamento.

- Analisar o efeito da hipóxia sobre a produção de progesterona e de 17ß-estradiol após 24 horas de tratamento. 
REVISÃO DE LITERATURA 


\section{REVISÃO DA LITERATURA}

Nesta seção são abordados temas referentes ao ciclo estral das cadelas, ressaltando as suas particularidades, e aos possíveis fatores regulatórios da função luteínica como a hipóxia, via fator indutível por hipóxia (HIF) $1 \mathrm{~A}$, modulando a expressão de fatores relacionados à angiogênese e à captação de glicose, tais como o fator de crescimento endotelial vascular (VEGF) e as proteínas transportadoras de glicose (GLUTs), respectivamente.

\subsection{O CICLO REPRODUTIVO DAS CADELAS}

As cadelas domésticas são monoéstricas, ovuladoras espontâneas não sazonais, com função luteínica que se reflete na produção de progesterona que dura de 55 a 75 dias (média de 65 dias) e aproximadamente 2 meses de gestação. Assim, o corpo lúteo é, em muitas instâncias, suficiente para manter uma gestação a termo sem o complemento de qualquer outro mecanismo específico - fenômeno crítico em espécies que não tem produção de progesterona ou gonadotrofinas placentárias. Essa condição de pseudogestação fisiológica, que ocorre após a ovulação, é observada em todos os carnívoros, tanto naqueles com ovulação espontânea (canídeos) como nos que apresentam ovulação induzida (felinos) e também é comparável às fases luteínicas prolongadas observadas em indivíduos histerectomizados de espécies que possuem mecanismo luteolítico agudo (CONCANNON, 2011).

O intervalo interestro tem duração de 5 a 12 meses, média de 6 - 7 na maioria das raças, e é potencialmente paralelo ao ciclo circanual endógeno. A ovulação ocorre em resposta ao surgimento abrupto de gonadotrofinas no final do proestro, resultando em elevação de hormônio luteinizante por $1-3$ dias e de hormônio folículo estimulante (FSH) por 1 - 4 dias. A ovulação ocorre de 48 a 60 horas após a onda de LH. Nas cadelas, ao contrário da maioria dos mamíferos, a maturação do oócito acontece na parte caudal das tubas uterinas, aproximadamente 2 dias após a ovulação, como nas raposas. Em humanos e em alguns roedores, o aumento pré-ovulatório na produção de progesterona folicular é acompanhado pelo aumento na progesterona periférica, utilizado para predizer o dia da ovulação, o que é similar nas cadelas (CONCANNON, 2011). 
O ciclo reprodutivo canino é classicamente dividido em quatro fases: 1 - proestro, com duração de 5 a 20 dias; 2 - estro, com duração de 5 - 15 dias; 3 - diestro (fase luteínica), de 50 a 75 dias e, 4 - anestro, com duração de 80 - 240 dias. Essas fases refletem, respectivamente, a fase folicular com predominância de estrógenos; o início da fase luteínica com aumento de progesterona e diminuição de estrógenos; a fase luteínica com predominância de progesterona e o intervalo entre a perda da função luteínica e o início do próximo ciclo. A duração de cada fase é variável devido ao longo período de receptividade no estro (4 - 12 dias) e pela possibilidade da ovulação ocorrer em qualquer momento após o fim do proestro e início do estro (HOFFMANN et al., 1999; CONCANNON, 2009).

Nas cadelas, o aumento inicial e o subsequente declínio da progesterona durante os ciclos prenhes e não prenhes são acompanhados por pequenas elevações de 17ß-estradiol após o final do estro, presumivelmente de origem luteínica e que, geralmente, são mais evidentes em cadelas prenhes. No diestro, a progesterona sérica atinge picos de $15-80 \mathrm{ng} / \mathrm{ml}$ entre os dias 20 e 35, e depois declina lentamente, atingindo níveis abaixo de $1 \mathrm{ng} / \mathrm{ml}$ por volta dos dias 55 - 90 (média 70). O estradiol é variável a valores intermediários de 15 - $30 \mathrm{pg} / \mathrm{ml}$, sendo mais elevado na metade do diestro e declinando depois (CONCANNON, 2009).

Em cadelas não prenhes, a regressão lenta da fase do corpo lúteo (CL) cuja funcionalidade equivale ao período de uma gestação é caracterizada pela diminuição na produção de progesterona (luteólise funcional), seguida pela diminuição do tamanho celular (luteólise estrut ural), durante a qual as células luteínicas sofrem apoptose (SONNACK, 2009), porém os mecanismos desencadeadores desse processo ainda não foram completamente elucidados e têm sido extensivamente estudados. O lento declínio de progesterona é associado com a progressiva redução na expressão da enzima esteroidogênica HSD3B a partir do dia 15 pós ovulação (po), a qual converte pregnenolona a progesterona (KOWALEWSKI et al., 2006a). A prostaglandina (PGF) endógena, diferentemente do que ocorre na cadela prenhe, parece não estar envolvida: a atividade luteínica de COX1 é baixa durante o diestro, enquanto a de COX2 aumenta apenas durante o rápido crescimento observado nas primeiras semanas após a onda de LH e, embora o receptor de prostaglandina seja constitutivamente expresso, o que explica a sensibilidade às prostaglandinas exógenas, não há evidência de expressão da PGF sintetase (KOWALEWSKI et al., 2006b). Além disso, o endométrio canino tem a capacidade de produzir PGF in vitro, mas em quantidades insuficientes para exercer algum efeito no corpo lúteo in vivo, uma vez que a histerectomia não tem efeito substancial (LUZ et al., 2006a). A lenta regressão luteínica durante 1 - 2 meses parece envolver funções celulares 
constitutivas: ela envolve baixa, mas evidente atividade apoptótica com aumento não aparente na produção de prostaglandina endógena (LUZ et al., 2006b; CONCANNON, 2009); células imunológicas CD8 e MHC-II positivas aumentam do dia 45 aos dias 60-75, porém, a expressão de citocinas não altera ao longo do diestro (HOFFMANN; BÜSGES; BAUMGÄRTNER, 2004; ENGEL et al., 2005) e não há o declínio de LH nem de prolactina ou de seus receptores que pudessem justificar essa lenta regressão (FERNANDES et al., 1987).

Em vacas, durante a luteólise, a diminuição no fluxo sanguíneo luteínico é paralela às concentrações de progesterona sistêmica (ACOSTA et al., 2002). Além disso, o conteúdo de oxigênio no sangue venoso ovariano começa a diminuir nos estágios finais da fase luteínica, o que indica que condições de hipóxia ocasionadas pela diminuição do suprimento sanguíneo seja parte característica do ambiente luteínico durante a luteólise (NISHIMURA et al., 2008).

\subsection{FATOR INDUTÍVEL POR HIPÓXIA 1 (HIF1)}

O fator indutível por hipóxia 1 consiste em um complexo ligante de DNA, identificado como componente chave de um amplo sistema de controle transcricional, respondendo a níveis fisiológicos de hipóxia celular (MAXWELL; PUGH; RATCLIFFE, 1993). Mudanças nas expressões gênicas direta ou indiretamente reguladas pelo HIF1 englobam mais de 100 genes envolvidos nos processos de adaptação metabólica, eritropoiese, angiogênese e tônus vascular, crescimento e diferenciação celular, sobrevivência e apoptose, isto é, em vias críticas para o desenvolvimento, fisiologia e patologias (MAXWELL; PUGH; RATCLIFFE, 2001).

O complexo HIF é composto por duas proteínas contendo o domínio hélice-girohélice básico Per-AHR-ARNT-Sim: o HIF1B constitutivo e uma das subunidades A induzidas por hipóxia, HIF1A ou HIF2A. Na hipóxia, o heterodímero A/B se liga a uma sequência central de pentanucleotídeos (RCGTG) dos elementos responsivos à hipóxia (HREs; do inglês hypoxia response elements) dos genes-alvo. As subunidades HIFB são proteínas nucleares não responsivas ao oxigênio e exercem outros papéis na transcrição, enquanto as subunidades HIFA são altamente induzidas pela hipóxia (WEIDEMANN; JOHNSON, 2008). 
Sob normóxia, as células sintetizam e degradam continuamente a proteína HIFA. No entanto, sob concentrações decrescentes de oxigênio, a degradação do HIFA é retardada (JIANG, B. H. et al., 1996; JEWELL et al., 2001). A interface entre o oxigênio e a proteína HIFA é provida por reações enzimáticas distintas: a hidroxilação de dois resíduos prolil (Pro402 e Pro564 no HIFA humano) no domínio de degradação oxigênio-dependente (ODDD) das subunidades A (IVAN et al., 2001; JAAKKOLA et al., 2001). Essa hidroxilação oxigênio-dependente regula a interação com a proteína supressora tumoral Von Hippel Lindau (VHL), a qual é um componente de reconhecimento do complexo E3 ubiquitina ligase que tem o HIF como alvo para proteólise via ubiquitina-proteassoma (MAXWELL et al., 1999; OHH et al., 2000). Sob hipóxia, a hidroxilação prolil é suprimida, a proteína HIF escapa da degradação proteassômica e se acumula. A mesma transloca-se para o núcleo e dimeriza-se com o HIFB. Esse complexo heterodimérico se liga, então, ao HRE das sequências promotoras dos genes-alvo (WEIDEMANN; JOHNSON, 2008).

O HIFA possui três isoformas: HIF1A, HIF2A e HIF3A, respectivamente, as quais são codificadas em locais distintos com variantes geradas por splicing alternativo. O HIF1A e o HIF2A compartilham arquitetura de domínio similar e são submetidos à regulação proteolítica semelhante; porém, enquanto o HIF1A é expresso pela maioria das células, o HIF2A possui um padrão de expressão mais restrito (NANGAKU; ECKARDT, 2007). A localização e o papel do HIF3A permanecem relativamente desconhecidos, mas a variante HIF3A4 atua como inibidora de HIF1A e HIF2A (HEIKKILÄ et al., 2011).

\subsubsection{HIF1A e angiogênese}

A partir de determinado tamanho, a difusão simples de oxigênio se torna inadequada para atender a demanda metabólica, especialmente em células de rápida proliferação como em embriões e tumores. Os três principais processos envolvidos na formação de novos vasos sanguíneos são referidos como vasculogênese, angiogênese e arteriogênese. O microambiente hipóxico ocasionado pelo aumento do consumo de oxigênio pela hipertrofia e/ou hiperplasia e a diminuição da distribuição de oxigênio devido ao aumento na distância de difusão contribuem para a angiogênese. Uma importante conexão entre a angiogênese e a hipóxia foi a descoberta de que a expressão do fator de crescimento endotelial vascular 
(VEGF) é induzida por hipóxia, via ligação do HIF1A ao elemento responsivo à hipóxia presente na região promotora do VEGF (WEIDEMANN; JOHNSON, 2008).

A família VEGF é constituída pelo VEGFA, VEGFB, VEGFC, VEGFD, VEGFE, fator de crescimento placentário (PGF) e seus receptores, VEGFR1 (FLT1, fms-like-tyrosine kinase receptor 1), VEGFR2 (KDR, kinase insert domain receptor), VEGFR3 e os coreceptores neutrofilina 1 e neutrofilina 2 (ANDRAWEERA et al., 2012). O VEGFA é considerado o principal fator angiogênico ovariano regulando os processos de foliculogênese e luteogênese (QUINTANA et al., 2004; ROBERTS et al., 2007; YANG et al., 2008). Juntamente com os seus receptores, FLT1 e KDR, o VEGFA foi identificado no corpo lúteo de humanos (OTANI et al., 1999; HARATA et al., 2006), camundongos (CELIK-OZENCI et al., 2003), suínos (BARBONI et al., 2000) e bovinos (PFARRER et al., 2006). Em cães, tanto nas células endoteliais quanto em células luteínicas expressam o sistema VEGF com aumento de expressão nos dias 10 e 50 após a ovulação (MARIANI et al., 2006).

Por recrutar células endoteliais para áreas avasculares e hipóxicas e estimular sua proliferação, o VEGFA é um dos principais genes-alvo do HIF1A. Demonstrou-se que a hipóxia induz a expressão gênica e protéica do VEGF, sugerindo que a hipóxia é um estímulo para a angiogênese através da regulação positiva da expressão do VEGF (NEUFELD et al., 1999; JOSKO et al., 2000). A indução da angiogênese leva a um aumento da densidade vascular e, conseqüentemente, a uma diminuição da distância de difusão do oxigênio. Porém, sob condições patológicas, o fluxo sangüíneo local é controlado pela modulação do tônus vascular pela produção de óxido nítrico sintetase (NOS), hemoxigenase 1 (CO), endotelina 1 , adrenomedulina ou ativação do receptor adrenérgico $\alpha_{1 \mathrm{~B}}$, todos os quais envolvem genes-alvo do HIF1 A (PALMER et al., 1998; NGUYEN; CLAYCOMB, 1999). Desse modo, o HIF1A contribui no processo de angiogênese através de múltiplos mecanismos, provavelmente, por recrutar genes-alvo adicionais envolvidos na maturação vascular (WENGER, 2002).

\subsubsection{HIF1A e adaptação metabólica}

Após a descoberta de que o sistema HIF é amplamente atuante na maioria das células e que essa ação não é restrita à regulação da eritropoietina, sítios de ligação do HIF1A foram identificados em genes codificadores das enzimas glicolíticas fosfoglicerato quinase $1 \mathrm{e}$ lactato desidrogenase A (FIRTH et al., 1994). Sucessivos estudos identificaram mais enzimas 
envolvidas nessa via metabólica que são estimuladas pela hipóxia: os transportadores de glicose (GLUTs) e as enzimas da gliconeogênese (WEIDEMANN; JOHNSON, 2008).

A família de proteínas facilitadoras transportadoras de glicose (GLUTs; gene SLC2A) pertence à superfamília de transportadores de membrana (MEF) e a maioria de seus membros catalisa a transferência bidirecional facilitadora (independente de energia) de seus substratos através de membranas (THORENS; MUECKLER, 2010). Os GLUTs são proteínas de aproximadamente 500 aminoácidos, dos quais foram identificados 14 membros (GLUT1 14) que podem ser agrupados em três diferentes classes, baseando-se na similaridade de suas sequências (JOOST et al., 2002). O GLUT1, GLUT3 e GLUT4 são os principais reguladores da captação de glicose devido ao seu padrão de expressão, número de moléculas por célula e grau de afinidade pela glicose (BROWN, 2000). Os mesmos foram identificados no ovário de bovinos (NISHIMOTO et al., 2006), ovinos (WILLIAMS et al., 2001), ratos (KOL et al., 1997; KODAMAN; BEHRMAN, 1999) e camundongos (ZHOU, J.; BIEVRE; BONDY, 2000) com diferenças consideráveis no perfil de expressão entre as espécies.

O GLUT1 é responsável pela captação basal e armazenamento de glicose em todas as células (MUECKLER, 1990) e abundantemente expresso em eritrócitos, no endotélio e margens epiteliais como barreira hematoencefálica, retina e placenta (HAHN; DESOYE, 1996). O GLUT3 é um transportador com alta afinidade pela glicose ( $\mathrm{Km} 1,5 \mathrm{mM})$ e é abundante em tecidos com intensa atividade metabólica tais como, cérebro, testículos e placenta (VON WOLFF et al., 2003). O GLUT4 tem sua importância por ser responsável pela homeostase de glicose no organismo, sendo regulado pela insulina, altamente expresso no músculo esquelético e tecido adiposo, e alterações nessa regulação se refletem em estados de resistência à insulina e patologias como a obesidade e o diabetes tipo 2 (THORENS; MUECKLER, 2010).

Uma vez que esses transportadores movem a glicose abaixo de seus gradientes de concentração a partir de concentrações sanguíneas relativamente altas para níveis relativamente baixos no meio intracelular, o simples aumento dessas proteínas reflete no aumento do fluxo de glicose no interior da célula hipóxica e, assim, o HIF1A foi identificado como o principal indutor desses transportadores, atuando via ligação ao elemento responsivo à hipóxia presente na região promotora do $S L C 2 A$ (DENKO, 2008). 
MATERIAL E MÉTODOS 


\section{MATERIAL E MÉTODOS}

Cadelas sem raça definida e clinicamente sadias foram submetidas à ovariosalpingohisterectomia (OSH) em dias específicos do diestro (dias 10, 20, 30, 40, 50, 60 e 70 após a ovulação; $\mathrm{n}=28 ; 4$ por grupo). A função ovariana foi monitorada pela determinação dos níveis séricos de progesterona, em dias alternados, a partir do surgimento dos sinais de proestro (edema e secreção vulvar sanguinolenta) e o dia da ovulação (dia 0) foi definido como o dia em que a concentração de progesterona atingiu valores = a $5 \mathrm{ng} / \mathrm{ml}$ (CONCANNON et al., 1989). No dia da intervenção cirúrgica, antes do início do protocolo anestésico (Acepromazina, 0,2 mg/kg IM; Xilazina, $3 \mathrm{mg} / \mathrm{kg}$ e Cloridrato de quetamina, 5 a 8 $\mathrm{mg} / \mathrm{kg}$ IV), amostras de sangue foram coletadas para as dosagens hormonais e de glicemia.

\subsection{DETERMINAÇÃO DE PROGESTERONA， 17?-ESTRADIOL， INSULINA E GLICOSE SÉRICA}

De cada animal, foram coletados $5 \mathrm{ml}$ de sangue total, por punção das veias jugular ou cefálica, os quais foram acondicionados em tubos sem anticoagulante e centrifugados a 1500 x g por 10 min a $4^{\circ} \mathrm{C}$ para a obtenção do soro, no qual foram avaliadas as concentrações séricas de progesterona, $17 ß$-estradiol e insulina por radioimunoensaio utilizando-se kits de fase sólida (Coat-a-Count RIA kits; Siemens Healthcare Diagnostics, EUA) e glicose pelo método enzimático colorimétrico em analisador automático a $505 \mathrm{~nm}$. Os soros sangüíneos foram mantidos a $-20^{\circ} \mathrm{C}$ até o seu processamento.

\subsection{ESTIMATIVA DA SENSIBILIDADE INSULÍNICA}

A sensibilidade insulínica basal foi estimada a partir das concentrações de glicose e insulina em jejum, baseando-se em nos seguintes índices: (1) relação insulina:glicose = insulinemia $(\mu \mathrm{U} / \mathrm{ml})$ / glicemia $(\mathrm{mg} / \mathrm{dl})$, (2) relação insulina:glicose corrigida (RI:GC) = insulinemia $(\mu \mathrm{U} / \mathrm{ml})$ x $100 /$ glicemia $(\mathrm{mg} / \mathrm{dl})$ - 30 (KOGIKA et al., 2001; FELDMAN; 
NELSON, 2004; PÖPPL et al., 2009) e (3) duas versões do HOMA (do inglês Homeostasis Model Assessment ou Modelo de Avaliação da Homeostase) (MATTHEWS et al., 1985; LEVY, J. C.; MATTHEWS; HERMANS, 1998). As duas versões do HOMA foram calculadas, primeiramente, com uma fórmula não linear (também conhecido como HOMA 2) (LEVY, J. C.; MATTHEWS; HERMANS, 1998) usando a calculadora HOMA versão 2.2.2 (Diabetes Trial University, Universidade de Oxford, UK) e, secundariamente, com fórmulas de aproximação linear $\mathrm{HOMA}_{\text {sensibilidade insulínica }}(\mathrm{HR})=$ insulinemia $\mathrm{x}$ glicemia / 22,5, (2) HOMA B $(\% \mathrm{~B})=20 \mathrm{x}$ insulinemia $(\mu \mathrm{U} / \mathrm{ml}) /$ glicemia $(\mathrm{mmol} / \mathrm{l})-3,5$ (MATTHEWS et al., 1985). As concentrações de insulina $<2,9 \mu \mathrm{U} / \mathrm{ml}$ foram colocadas como 2,9, a mínima concentração aceita pela calculadora HOMA (VERKEST et al., 2010).

O experimento foi realizado em duas etapas: na primeira parte, amostras de corpo lúteo foram submetidas à análise da distribuição tecidual e quantificação das proteínas HIF1A, GLUT1 e GLUT4 e da expressão gênica de HIF1A, SLC2A1, SLC2A4, VEGFA, FLT1 e KDR pelos métodos de imuno-histoquímica, western blotting e PCR em tempo real, respectivamente. Na segunda, células luteínicas de cadelas nos dias 10, 30 e 60 após a ovulação foram isoladas e cultivadas sob condições de normóxia e de hipóxia por 24 horas e submetidas à análise de expressão gênica e dosagens hormonais.

\subsection{IMUNO-HISTOQUÍMICA PARA HIF1A, GLUT1 E GLUT4}

Para a imuno-histoquímica (IHC), amostras de corpo lúteo foram fixadas em formol tamponado a $4 \%$ por 24 horas. Depois de lavadas com solução tampão fosfato (PBS; $\mathrm{Na}_{2} \mathrm{HPO}_{4}$ 0,8 mM; $\mathrm{KH}_{2} \mathrm{PO}_{4}$ 1,47 mM; KCl 2,68 mM e NaCl $137 \mathrm{mM}$ ) e desidratadas em uma série graduada de etanol (70\%, 90\% e absolutos I, II e III; 1 hora cada), as amostras foram clareadas em xilol (I, II e III; 1 hora cada) e embebidas em parafina (I, II e de inclusão; 1 hora cada). Cortes de $2 \mu \mathrm{m}$ foram desparafinizados em xilol ( 2 x $10 \mathrm{~min}$ ), reidratados em uma série decrescente de etanol (etanol 100\% 2x5 min, etanol 95\% $5 \mathrm{~min}$, etanol $70 \% 5 \mathrm{~min}$ ) e lavados em água destilada (5 min). A recuperação antigênica ocorreu incubando-se em solução tampão citrato $10 \mathrm{nM}, \mathrm{pH}$ 6, por 5 minutos, à temperatura ambiente, seguida por 15 minutos de irradiação em micro-ondas em potência alta (560W). Em seguida, as lâminas foram resfriadas por 20 minutos à temperatura ambiente e lavadas em água destilada por 5 minutos. A atividade da peroxidase endógena foi bloqueada incubando-se as lâminas em peróxido de 
oxigênio a $1 \%$ diluído em metanol por 30 minutos, em freezer. As mesmas foram lavadas em tampão ICC / Triton X 0,3\%, pH 7,2 - 7,4 (PBS + $3 \mathrm{ml}$ de Triton X / litro), três vezes de 5 minutos, e incubadas em caseína (Protein block Serum-Free, X0909, Dako North America, Inc) por 20 minutos, à temperatura ambiente, para bloquear sítios de ligações inespecíficas. Após a secagem do bloqueador, os anticorpos primários (Quadro 1) foram aplicados sobre os cortes, os quais foram incubados overnight a $4^{\circ} \mathrm{C}$. Os controles negativos foram incubados com um anticorpo monoclonal irrelevante, isotipo específico, em concentração igual ao do respectivo anticorpo primário (Coulter Immunotech Diagnostics, Alemanha). Após lavagem em tampão ICC por três vezes de 5 minutos, o anticorpo secundário biotinilado (Biotinylated Link; kit Dako LSAB + System-HRP, K0679, Dako North America, Inc) foi adicionado e as lâminas incubadas por 15 minutos à temperatura ambiente. As mesmas foram lavadas em tampão ICC por três vezes de 5 minutos e incubadas com o complexo estreptavidinaperoxidase (Streptavidin-HRP; kit Dako LSAB + System-HRP, K0679, Dako North America, Inc) por 15 minutos, à temperatura ambiente. Após lavagem com tampão ICC por três vezes de 5 minutos, a reação de imuno-histoquímica foi iniciada com o cromógeno DAB (DAB + Subtrate buffer; kit Dako LSAB + System-HRP, K0679, Dako North America, Inc) por aproximadamente 60 segundos. Em seguida, as lâminas foram lavadas duas vezes de 5 minutos em água destilada, rapidamente contracoradas com hematoxilina (aproximadamente 30 segundos), lavadas em água corrente por 10 minutos, reidratadas em uma série graduada de álcool (70\%, 95\%, II e I; 2 minutos cada) e xilol (II e I; 2 minutos cada) e, finalmente, montadas com Permount ${ }^{\circledR}$ (Thermo Fisher Scientific Inc, EUA).

\subsection{WESTERN BLOTTING PARA HIF1A, GLUT1 E GLUT4}

Amostras de corpo lúteo foram homogeneizadas em tampão de homogeneização pH 7,4 (Tris $10 \mathrm{mM}$, EDTA $1 \mathrm{mM}$ e sacarose $250 \mathrm{mM}$ ) em um homogeneizador de tecidos (Bio-Gen PRO 200, PRO Scientific Inc., EUA) em gelo e centrifugados a 10.000 x g por 10 min a $4{ }^{\circ} \mathrm{C}$. O sobrenadante resultante foi utilizado para análise protéica de HIF1A, GLUT1 e GLUT4. A concentração de proteínas determinada pelo método de bradford, usando BSA como padrão (BRADFORD, 1976). As proteínas foram solubilizadas em tampão de amostra (25 mmol/l de Tris- $\mathrm{Cl}, \mathrm{pH}$ 6,8, SDS a 1\%, $\beta$-mercaptoetanol a 5\%, glicerol a $10 \%$ e bromophenol blue a $0.01 \%$ ) de acordo com as suas respectivas concentrações e aquecidas a $95^{\circ} \mathrm{C}$ por $5 \mathrm{~min}$ em 
termociclador (Mastercycle Gradiente HX0128-000208, Eppendorf, Alemanha). As amostras $(50 \mu \mathrm{g})$ foram submetidas à eletroforese SDS-page (HIF1A: 10\% SDS-page; GLUT1 e GLUT4: $12 \%$ SDS-page) por 1 hora a $100 \mathrm{~V}$. As proteínas foram transferidas eletroforeticamente para membranas PVDF (Bio-Rad Laboratories, Inc.) por $2 \mathrm{~h}$ a $400 \mathrm{~V}$ em tampão de transferência pH 8,3 (Tris 25 mM, glicina $192 \mathrm{mM}$, SDS a 1\% e metanol a 20\%). As membranas foram incubadas em tampão de bloqueio (leite desnatado a 5\% em TBS-T [Tween 20 a $0,1 \%$ em TBS (Tris $1 \mathrm{M} \mathrm{pH} \mathrm{7,6} \mathrm{e} \mathrm{NaCl} 5 \mathrm{M}$ ]) por 1 hora, temperatura ambiente. Após o bloqueio, as membranas foram incubadas com o anticorpo primário específico para cada proteína (Tabela 1) overnight a $4{ }^{\circ} \mathrm{C}$. Após a incubação, as membranas foram lavadas três vezes de 10 min com TBS-T à temperatura ambiente, e incubadas com o anticorpo secundário (para HIF1 A [1:7500 em tampão de bloqueio] e GLUT4 [1:2000] anti-coelho IgG, HRP-conjugado, NIF824, Amersham GE Healthcare; para GLUT1 [1:5000] anti-cabra IgG e ACTB [1:500], anti-camundongo IgG, HRP-conjugado, NIF825, Amersham GE Healthcare) por 1 hora e lavadas três vezes em TBS por $10 \mathrm{~min}$ à temperatura ambiente. $\mathrm{O}$ sinal foi detectado utilizando-se o sistema de detecção para western blotting ECL (ECL ${ }^{\mathrm{TM}}$, Amersham GE Healthcare, RPN2109, UK).

A intensidade da reação nos tecidos foi estimada pela mensuração da densidade óptica em área definida por densitometria computadorizada usando o programa ImageJ 1.38X (National Institutes of Health, EUA).

Quadro 1 - Anticorpos primários utilizados nas técnicas de imuno-histoquímica e western blotting

\begin{tabular}{|c|c|c|c|c|}
\hline Anticorpos & Isotipo & Epitopo & Diluição & Fornecedor $\left(\mathbf{n}^{\circ}\right)$ \\
\hline HIF1A & IgG polyclonal de coelho & $432-528$ HIF1A humano & $1: 500$ & Novus Biologicals (NB100-134) \\
GLUT1 & IgG policlonal de cabra & C-terminal humano & $1: 500$ & Santa Cruz (C-20; sc-1605) \\
GLUT4 & IgG polyclonal de coelho & C-terminal humano & $1: 1200$ & Milipore (07-1404) \\
VEGFA & IgG policlonal de coelho & N-terminal humano & $1: 500$ & Santa Cruz(A-20; sc-152) \\
ACTB & Monoclonal de camundongo & N-terminal ACTB modificada & $1: 500$ & Sigma-Aldrich (Clone AC-15; A1978) \\
\hline
\end{tabular}




\subsection{EXPRESSÃO GÊNICA DE HIF1A, SLC2A1, SLC2A4, VEGFA, FLT1 E KDR NO CORPO LÚTEO CANINO}

O RNA total foi extraído do tecido luteínico $(0,2 \mathrm{~g})$ e de células luteínicas cultivadas utilizando-se o reagente TRIzol ${ }^{\circledR}$, de acordo com as instruções do fabricante (Invitrogen ${ }^{\mathrm{TM}}$ Corporation, EUA). As amostras foram homogeneizadas vigorosamente em vórtex por 10 segundos e centrifugadas a 12.000 x g por 10 minutos a $4{ }^{\circ} \mathrm{C}$. Após a centrifugação, o sobrenadante foi transferido para um tubo estéril livre de RNAse (de 1,5 ml) contendo $200 \mu \mathrm{l}$ de clorofórmio, o qual foi homogeneizado vigorosamente em vórtex por 10 segundos, incubado à temperatura ambiente por 3 minutos e centrifugado a 12.000 g por 15 minutos a 4 ${ }^{\circ} \mathrm{C}$. Para a precipitação do RNA, o sobrenadante aquoso foi transferido para um tubo estéril de $1,5 \mathrm{ml}$ contendo $500 \mu \mathrm{l}$ de álcool isopropílico, incubado por 10 minutos à temperatura ambiente e centrifugado a 12.000 g por 15 minutos a $4{ }^{\circ} \mathrm{C}$. O sobrenadante foi descartado e ao tubo foi adicionado $500 \mu \mathrm{l}$ de etanol a $75 \%$. Os mesmos foram centrifugados a $7.500 \mathrm{~g}$ por 5 minutos a $4{ }^{\circ} \mathrm{C}$ e o sobrenadante descartado. O RNA precipitado foi eluído em água ultrapura (10 e $20 \mu$ l para células e tecido, respectivamente) e armazenado em freezer $-80^{\circ} \mathrm{C}$. A concentração e pureza do RNA foram determinadas através de um bioespectrofotômetro (Eppendorf, Alemanha) na razão de 260/280 nm e a integridade em gel de agarose a $2 \%$.

\subsubsection{Transcrição reversa e síntese de cdna}

Para eliminar o DNA genômico, o RNA extraído foi tratado com DNAse I (Kit SuperScript III; Invitrogen, Carlsbad, EUA), de modo que a solução final contivesse $1 \mu \mathrm{g} / \mu 1$ de RNA total usando o kit . A esta solução foram adicionados: $1 \mu 1$ de tampão DNAse, $1 \mu 1$ de DNAse I e água ultrapura, completando-se para o volume de $9 \mu 1$. Para inativar a atividade da DNAse I, foi adicionado $1 \mu \mathrm{l}$ de EDTA. Após incubação por 10 minutos a $65^{\circ} \mathrm{C}$, foram adicionados os iniciadores da reação, Oligo (dt) e dNTP $10 \mu \mathrm{M}(1 \mu \mathrm{l}$ cada), incuboutse por 5 minutos a $65^{\circ} \mathrm{C}$ e por 1 minuto e 30 segundos em gelo. Em seguida, foram adicionados $4 \mu 1$ de tampão, $1 \mu 1$ de DTT (0,1M), $1 \mu 1$ de inibidor RNAse (RNAse OUT Inhibitor) e $1 \mu 1$ da enzima SuperScript III. Tubos estéreis de $0,5 \mathrm{ml}$ contendo o RNA e os compostos para a síntese de cDNA foram colocados no termociclador (Mastercycle Gradiente HX0128-000208, 
Eppendorf, Alemanha), onde permaneceram por 50 minutos a $50^{\circ} \mathrm{C}$, para ocorrer a transcrição do RNA em cDNA e, posteriormente, por 15 minutos a $70^{\circ} \mathrm{C}$ e 2 minutos a $4^{\circ} \mathrm{C}$ para inativação da enzima. Os cDNAs foram armazenados a $-20^{\circ} \mathrm{C}$.

As reações de PCR foram realizadas em fluorometro automatizado (ABI PRISM ${ }^{\mathrm{TM}}$ 7500, Applied Biosystems, USA), usando placas ópticas de 96 poços. Todas as amostras foram analisadas em duplicata. Primeiramente, os cDNAs foram diluídos em água ultrapura autoclavada na proporção de 1:8, em gelo. Em seguida, foi preparado um mix para cada gene estudado contendo: 6,25 $\mu 1$ de TaqMan $^{\circledR}$ qPCR MasterMix, 3,25 $\mu 1$ de água ultrapura autoclavada e $0,5 \mu \mathrm{l}$ de primers sense e anti-sense $900 \mathrm{mM}$ e sonda $250 \mathrm{mM}$ (Quadro 2), totalizando $10 \mu \mathrm{l}$ para cada amostra. Este mix foi pipetado na placa e recebeu imediatamente 2,5 $\mu 1$ da respectiva amostra de cDNA na concentração de 125 ng. Após pipetar todas as amostras nos poços, a placa foi vedada com um parafilme óptico próprio, submetida à centrifugação rápida (menos de 1 minuto) e levada ao aparelho de PCR. As condições de PCR foram: denaturação por 10 minutos a $95^{\circ} \mathrm{C}$, seguida por 40 ciclos a $95^{\circ} \mathrm{C}$ por 15 segundos e $60^{\circ} \mathrm{C}$ por 1 minuto.

As quantificações relativas de HIF1A, SLC2A1, SLC2A4, VEGFA, FLT1 e KDR foram realizadas normalizando-se os sinais de expressão desses genes com o sinal da ciclofilina A (gene PPIA; Tabela 2) como controle endógeno, através do programa LinRegPCR ${ }^{\circledR}$ versão 7.0 (RAMAKERS et al., 2003), seguido do método matemático de Pfaffl (PFAFFL et al., 2001) e análise estatística dos dados. 
Quadro 2 - Primers e sondas utilizados no PCR em tempo real

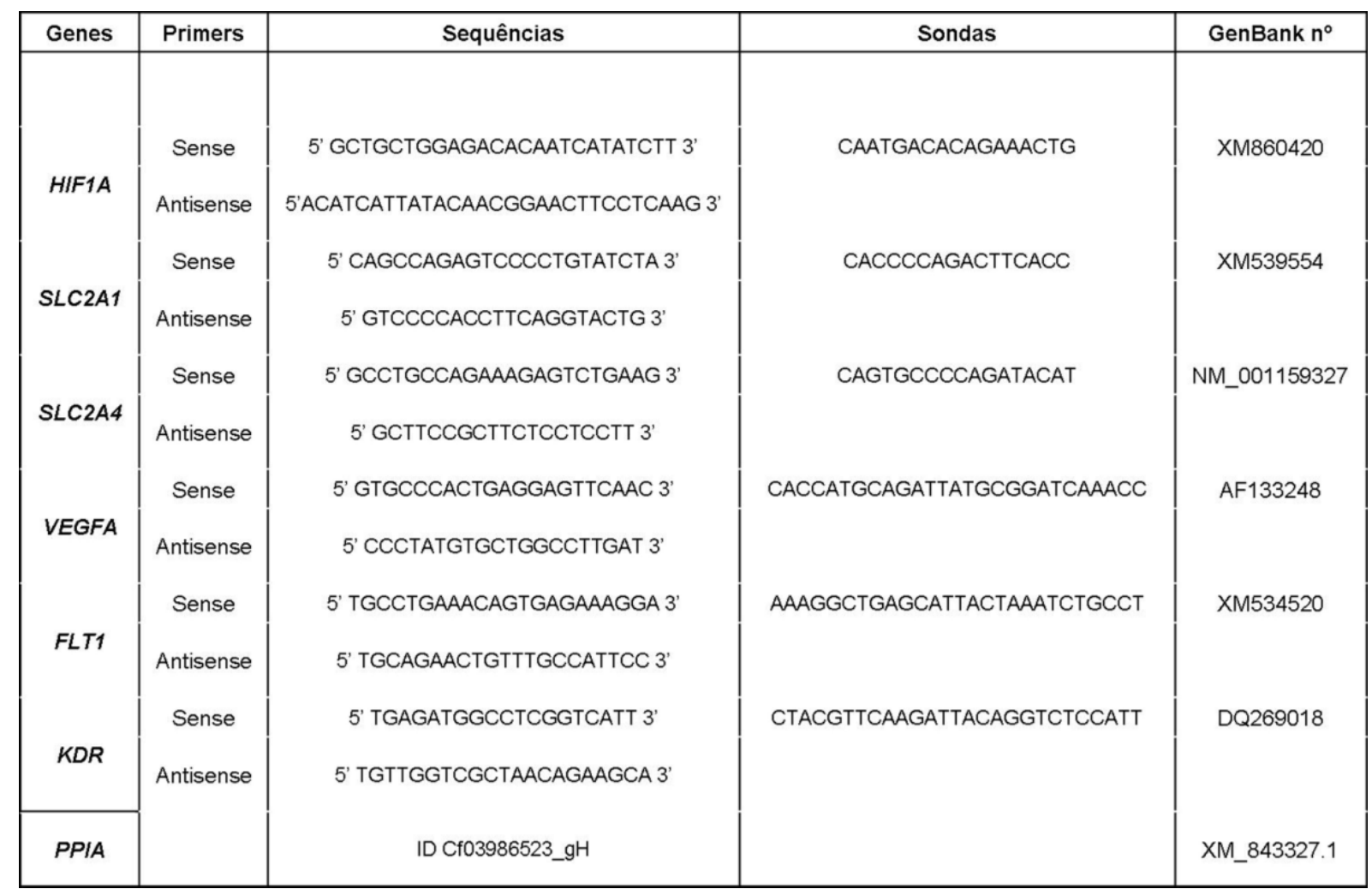

\subsection{ISOLAMENTO DAS CÉLULAS LUTEÍNICAS}

Os ovários com corpos lúteos de cadelas nos dias 10, 30 e 60 após a ovulação ( $n=4$ animais / grupo, dias específicos determinados após avaliação da expressão do HIF1A em tecido luteínico ao longo do diestro) foram coletados imediatamente após a remoção cirúrgica, imersos em solução tampão fosfato (PBS) contendo solução antibiótica e antimicótica a $1 \%$ (10.000 UI de penicilina, $10 \mathrm{mg}$ de estreptomicina e $25 \mu \mathrm{g}$ de anfotericina B por $\mathrm{ml}$; A5955; Sigma Aldrich, USA) e transportados em gelo ao laboratório. Em capela de fluxo laminar (Pachane Pa420, Pachane Equipamentos para Laboratórios LTDA, Brasil), o tecido ovariano adjacente foi dissecado e o tecido luteínico remanescente foi dissociado enzimaticamente com colagenase tipo 1 ( $1 \mathrm{mg} / \mathrm{ml}$; C0130; Sigma Aldrich, USA) diluída em DMEM pH 7,2 - 7,4 (41965-039; Gibco BRL) por 1 hora sob agitação (60 movimentos / min) à temperatura de 37 ${ }^{\circ} \mathrm{C}$ em atmosfera úmida com $5 \%$ de $\mathrm{CO}_{2}$. As células foram suspensas em meio de cultura DMEM contendo soro fetal bovino a 10\% (Sigma Aldrich, USA), L-glutamina a 1\% (Sigma Aldrich, USA), HEPES 20 mM (Sigma Aldrich, USA) e solução antibiótica e antimicótica a 1\% (A5955; Sigma Aldrich, USA). A viabilidade celular foi maior que $80-90 \%$, conforme o 
método de exclusão pelo azul de trypan. A suspensão celular foi centrifugada a $200 \mathrm{x}$ g por 10 min, ressuspensa em DMEM e filtrada em rede de $70 \mu \mathrm{m}$ de diâmetro para remover os tecidos não digeridos. O filtrado foi novamente centrifugado a 200 x g por $10 \mathrm{~min}$, ressuspenso em solução tampão de lise de eritrócitos $\left(0,16 \mathrm{M} \mathrm{NH}_{4} \mathrm{Cl}\right.$ e $0,01 \mathrm{M}$ Tris-HCl; pH 7,2-7,4) diluído em DMEM (v/v) por $10 \mathrm{~min}$, centrifugado a 200 x g por $10 \mathrm{~min}$ e ressuspenso em DMEM. As células luteínicas dispersas foram cultivadas em placas de 24 poços (costar ${ }^{\circledR} 3524$; Corning Inc., EUA) para determinação das expressões gênica e protéica e produção de progesterona.

\subsubsection{Efeito da hipóxia na função luteínica}

As células luteínicas foram mantidas em DMEM suplementado com soro fetal bovino a $10 \%$ até atingirem $80-90 \%$ de confluência. O meio de cultivo foi removido e trocado por DMEM sem soro por $24 \mathrm{~h}$. Após a privação de soro, as células foram tratadas com cloreto de cobalto $\left(\mathrm{CoCh}_{2}\right.$; Sigma-Aldrich, St. Louis, EUA) na concentração de $500 \mu \mathrm{M}$ determinada através de uma curva de dose-resposta (Figura 1) e incubadas por 24 horas. O meio de cultivo foi coletado para mensuração de progesterona por radioimunoensaio e as células, coletadas em TRIzol ${ }^{\circledR}$ para análise por PCR em tempo real, conforme item 4.5. 
Figura 1 - Efeito das concentrações crescentes de CoCl2 $(0-1000 \mu \mathrm{M})$ na expressão do HIF1A em células luteínicas caninas oriundas do dia 10 após a ovulação. A expressão protéica e gênica foi determinada por western blotting e PCR em tempo real, respectivamente, após 24 horas do início do tratamento. As proteínas totais isoladas de homogenatos de tecido luteínico foram detectadas com anticorpos específicos e normalizados com a expressão de ACTB, enquanto as quantificações relativas da expressão do RNAm do HIF1A foram normalizadas com a expressão da ciclofilina A como controle endógeno. Os dados são expressos como média \pm DP. Barras com letras diferentes: $\mathrm{p}<0,05$.
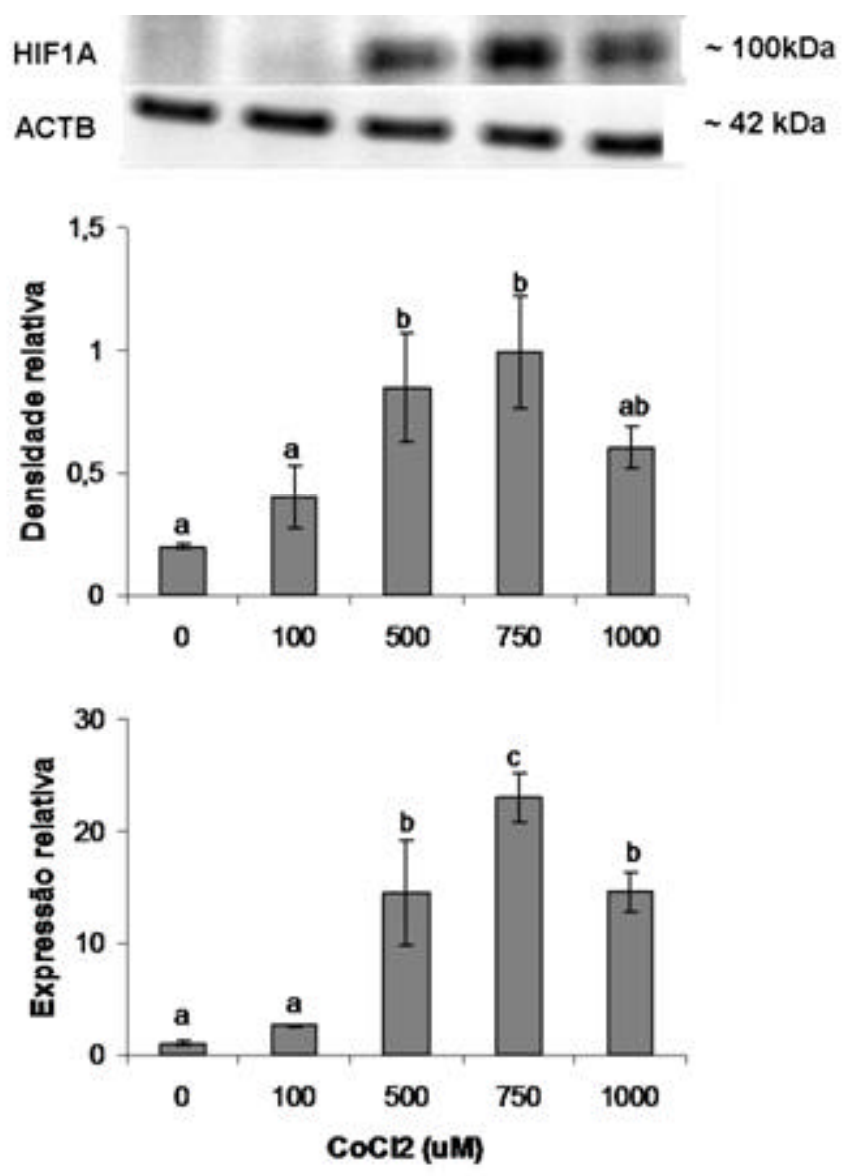

\subsection{ANÁLISE ESTATÍSTICA}

No presente estudo, as variáveis dependentes foram: a produção hormonal e a expressão protéica e/ou gênica do HIF1A, sistema VEGF e transportadores de glicose, GLUT1 e GLUT4. Na primeira fase experimental, o efeito do dia do diestro (dias 10 - 70 após a ovulação) foi testado através do teste ANOVA de uma via seguido pelo teste de comparação múltipla de Tukey. Além disso, as variáveis foram confrontadas entre si pelo teste de correlação de Pearson. Na segunda fase, os dados foram transformados em raiz quadrada para normalizar as distribuições. Os efeitos do dia do diestro e do tratamento in vitro $(\mathrm{CoCl} 2$ a 0 ou $500 \mu \mathrm{M})$, bem como interações duplas foram testados por ANOVA de uma via em um arranjo $2 \times 2$ fatorial seguido pelo teste de comparação múltipla de Tukey. Os resultados foram apresentados por média \pm desvio padrão. Resultados estatísticos 
significativos foram considerados quando $\mathrm{p}=0,05$. Todos os cálculos foram analizados através do programa estatístico GraphPad Prism 4.0 (GraphPad Software, San Diego, USA). 
RESULTADOS 


\section{RESULTADOS}

\subsection{PERFIL SÉRICO DE PROGESTERONA E 17? -ESTRADIOL}

As concentrações de progesterona periférica aumentaram no início do diestro, atingindo o pico de 22,96 ng/ml no dia 20 após a ovulação, diminuindo abruptamente entre os dias 20 e $30(5,30 \mathrm{ng} / \mathrm{ml})$, e depois gradativamente até o dia $70(0,68 \mathrm{ng} / \mathrm{ml}$; Figura 2A). As concentrações de 17ß-estradiol aumentaram continuamente do dia 10 ao dia 40, quando alcançou a máxima de 27,34 pg/ml, passando a diminuir até o final do diestro (13,53 pg/ml; Figura 2B).

Figura 2 - Concentrações séricas de progesterona (ng/ml; A) e 17ß-estradiol (pg/ml; B) em cadelas ao longo do diestro (dias 10 - 70 após a ovulação). Dados representados por média \pm desvio padrão $(\mathrm{n}=3-4$ animais/grupo). Asteriscos indicam diferença significativa $(\mathrm{p}<0,05)$ em relação aos demais dias observados
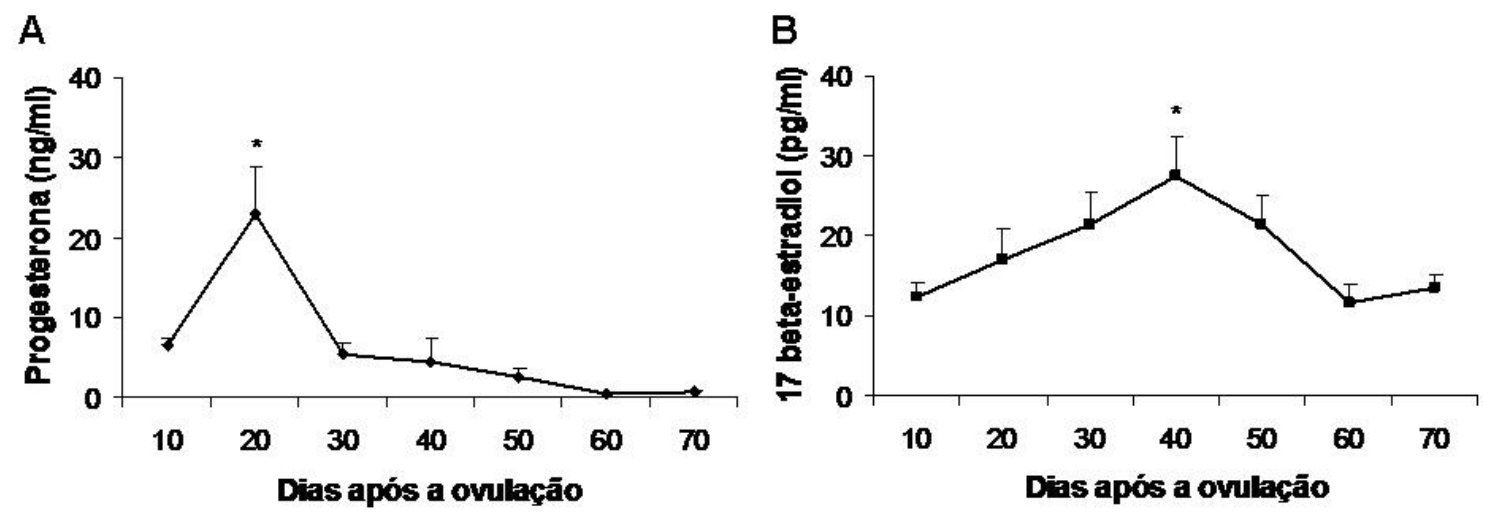

\subsection{PERFIL SÉRICO DE GLICOSE, INSULINA E ÍNDICES DE SENSIBILIDADE INSULÍNICA}

O perfil glicêmico mostrou-se constante no decorrer do diestro ( $p>0,05$; Figura 3A) e os animais utilizados no presente estudo encontravam-se normoglicêmicos (valores de referência: glicose entre 80 e $120 \mathrm{mg} / \mathrm{dl}$; KOGIKA et al., 2001; FELDMAN; NELSON, 2004). Já no perfil insulinêmico, as maiores concentrações foram observadas nos dias 10 e 40 após a ovulação (Figura 3B), porém, os valores estavam abaixo dos valores de referência 
(valor de referência: insulina entre 5 e $20 \mu \mathrm{UI} / \mathrm{ml}$; KOGIKA et al., 2001; FELDMAN; NELSON, 1996).

Figura 3 - Concentrações séricas de glicose $(\mathrm{mg} / \mathrm{dl}$; A) e insulina $(\mu \mathrm{U} / \mathrm{ml}$; B) em cadelas ao longo do diestro (dias $10-70$ após a ovulação). Dados representados por média \pm desvio padrão $(\mathrm{n}=3-4$ animais/grupo). Asteriscos indicam diferença significativa $(\mathrm{p}<0,05)$ em relação aos demais dias observados
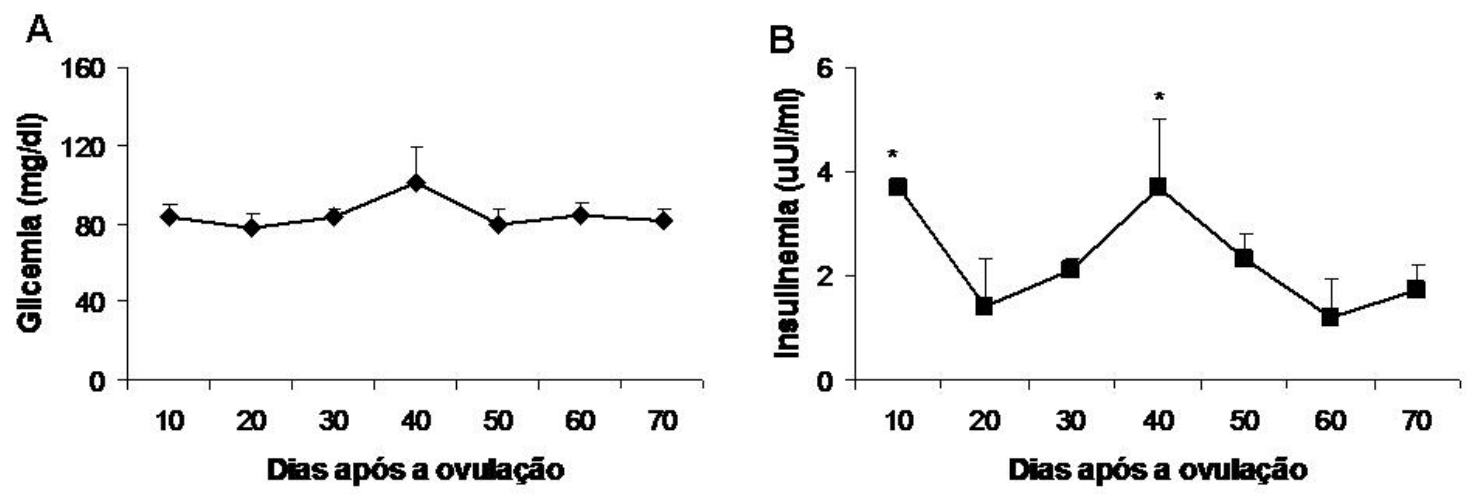

Na tabela 1, são demonstrados os valores médios obtidos para os índices relativos de insulina:glicose e/ou insulina:glicose corrigida, bem como para os índices HOMA 2 e HOMA não linear.

Tabela 1 - Média e desvio padrão dos valores obtidos para os índices de relação insulina:glicose, relação insulina:glicose corrigida, HOMA2 e HOMA em cadelas ao longo do diestro

\begin{tabular}{|c|c|c|c|c|c|c|c|}
\hline \multirow[t]{2}{*}{$\begin{array}{l}\text { Diestro } \\
\text { (dias) }\end{array}$} & \multirow[t]{2}{*}{$\begin{array}{c}\text { Relação } \\
\text { insulina:glicose }\end{array}$} & \multirow{2}{*}{$\begin{array}{c}\text { Relação } \\
\text { insulina:glicose } \\
\text { corrigida }\end{array}$} & \multicolumn{3}{|c|}{ HOMA $2^{a}$} & \multicolumn{2}{|c|}{ HOMA $^{a}$} \\
\hline & & & $\% \mathrm{~B}^{\mathrm{b}}$ & $\% \mathbf{S}^{c}$ & $\mathbf{R}^{\mathrm{d}}$ & $\% \mathrm{~B}^{\mathrm{b}}$ & $\mathbf{R}^{\mathrm{d}}$ \\
\hline 10 & $0,05 \pm 0,00^{*}$ & $8,4 \pm 0,0^{*}$ & $86,2 \pm 0,0^{*}$ & $217,8 \pm 0,0$ & $0,5 \pm 0,0^{*}$ & $117,8 \pm 0,0^{*}$ & $0,7 \pm 0,0^{*}$ \\
\hline 20 & $0,02 \pm 0,01$ & $2,7 \pm 1,5$ & $66,4 \pm 11,9$ & $263,4 \pm 21,1$ & $0,4 \pm 0,0$ & $35,5 \pm 14$ & $0,3 \pm 0,1$ \\
\hline 30 & $0,02 \pm 0,00$ & $4,2 \pm 0,02$ & $55,4 \pm 5$ & $266,8 \pm 6,2$ & $0,4 \pm 0,0$ & $35,5 \pm 6,2$ & $0,4 \pm 0,1$ \\
\hline 40 & $0,04 \pm 0,03^{*}$ & $6,6 \pm 3,09^{*}$ & $68,1 \pm 24,5^{\star}$ & $190,7 \pm 60,9$ & $0,6 \pm 0,2^{*}$ & $28,1 \pm 17,8$ & $0,9 \pm 0,3^{*}$ \\
\hline 50 & $0,02 \pm 0,00$ & $3,7 \pm 0,34$ & $48,0 \pm 3,9$ & $261,9 \pm 5,4$ & $0,4 \pm 0,0$ & $28,5 \pm 0,7$ & $0,5 \pm 0,1$ \\
\hline 60 & $0,02 \pm 0,01$ & $2,5 \pm 1,52$ & $60,0 \pm 8,7$ & $269,2 \pm 11$ & $0,4 \pm 0,0$ & $34,5 \pm 24,6$ & $0,2 \pm 0,1$ \\
\hline 70 & $0,02 \pm 0,01$ & $3,5 \pm 1,23$ & $61,3 \pm 8,9$ & $269,9 \pm 10,7$ & $0,4 \pm 0,0$ & $49,3 \pm 29,8$ & $0,4 \pm 0,1$ \\
\hline \multicolumn{8}{|c|}{ aModelo de Avaliação da Homeostase, calculado usando fórmula não linear em calculadora própria (HOMA 2) ou fórmula de aproximação linear (HOMA) } \\
\hline \multicolumn{8}{|c|}{ 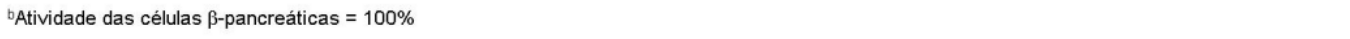 } \\
\hline \multicolumn{8}{|c|}{ 'Sensibilidade à insulina $=100 \%$} \\
\hline \multicolumn{8}{|c|}{ dResistência à insulina = 1} \\
\hline "Diferença & ignificativa $=p<0,05$ & & & & & & \\
\hline
\end{tabular}

A 
o analisarmos os índices relativos, observou-se que os animais não apresentaram hiperinsulinemia relativa (valor de referência > 0,235) e/ou hiperinsulinemia relativa corrigida (valor de referência > 30; KOGIKA et al ., 2001; FELDMAN; NELSON, 2004) e que ambos são diretamente relacionados com as concentrações de insulina $(r=0,90 ; p=0,005$ para relação insulina:glicose e $r=0,95 ; \mathrm{p}<0,001$ para relação insulina:glicose corrigida) com os maiores valores observados nos dias 10 e 40 após a ovulação.

Quanto aos índices HOMA, observou-se correlação direta entre os dois métodos tanto para a estimativa da resistência à insulina $(\mathrm{r}=0,91 ; \mathrm{p}=0,003)$ quanto para a estimativa da capacidade funcional das células beta pancreáticas $(r=0,82 ; p=0,02)$. Os maiores índices de resistência à insulina foram observados nos dias 10 e 40 após a ovulação e tanto o HOMA 2 quanto o HOMA não linear foram diretamente correlacionados com a produção de insulina ( $\mathrm{r}$ $=0,86 ; \mathrm{p}=0,01$ e $\mathrm{r}=0,96 ; \mathrm{p}<0,001$, respectivamente).

\subsection{EXPRESSÃO ESPAÇO-TEMPORAL DE HIF1A, GLUT1 E GLUT4 NO CORPO LÚTEO CANINO AO LONGO DO DIESTRO}

A distribuição tecidual das proteínas HIF1A, GLUT1 e GLUT4 foram analisadas por imuno-histoquímica, a qual revelou que as mesmas foram expressas de maneira uniforme no corpo lúteo (Figuras 4, 5 e 6). O HIF1A ficou restrito ao citoplasma das células luteínicas, endoteliais e estromais nos dias 10 e 20 após a ovulação (Figuras 4A e 4B). No dia 30, além da marcação citoplasmática, observou-se sinalização nuclear do HIF1A (Figura 4C). Nos dias 40 e 50, observou-se fraca marcação nuclear e sinal citoplasmático mais evidente no dia 40 que no dia 50 (Figuras 4D e 4E) e nos dia 60 e 70 após a ovulação, tanto o sinal citoplasmático quanto o nuclear tornaram-se mais intensos (Figuras 4F e 4G). A marcação nuclear do HIF1A foi observada somente nas células luteínicas (Figuras 4C e 4F). No entanto, macrófagos e células endoteliais também expressaram HIF1A em seus citoplasmas (Figuras 4B e 4D).

As proteínas GLUT1 e GLUT4 foram detectadas no meio intracelular de células luteínicas, endoteliais e do stroma em todos os períodos investigados (dias 10 a 70 após a ovulação), sendo que a expressão temporal foi mais intensa na primeira metade do diestro (dias 10 - 30; Figuras 5 e 6; A-D) quando comparado com a segunda (Figuras 5 e 6; E-H). 
Figura 4 - Imunolocalização do HIF1A no corpo lúteo canino ao longo do diestro. (A e B) Dias 10 e 20: a proteína HIF1A é detectada no citoplasma (coloração marrom) de células luteínicas, endoteliais e estromais. (C) Dia 30: o HIF é observado tanto no citoplasma quanto no núcleo das células luteínicas (setas brancas). (D e E) Dias 40 e 50: nesse período, a intensidade da reação tanto no núcleo quanto no citoplasma encontra-se reduzida. (F e G) Dias 60 e 70: observa-se intensa reação nuclear e citoplasmática. (H) Placenta humana: controle positivo. (I) Dia 20: controle negativo. Barras $=20 \mu \mathrm{m}$

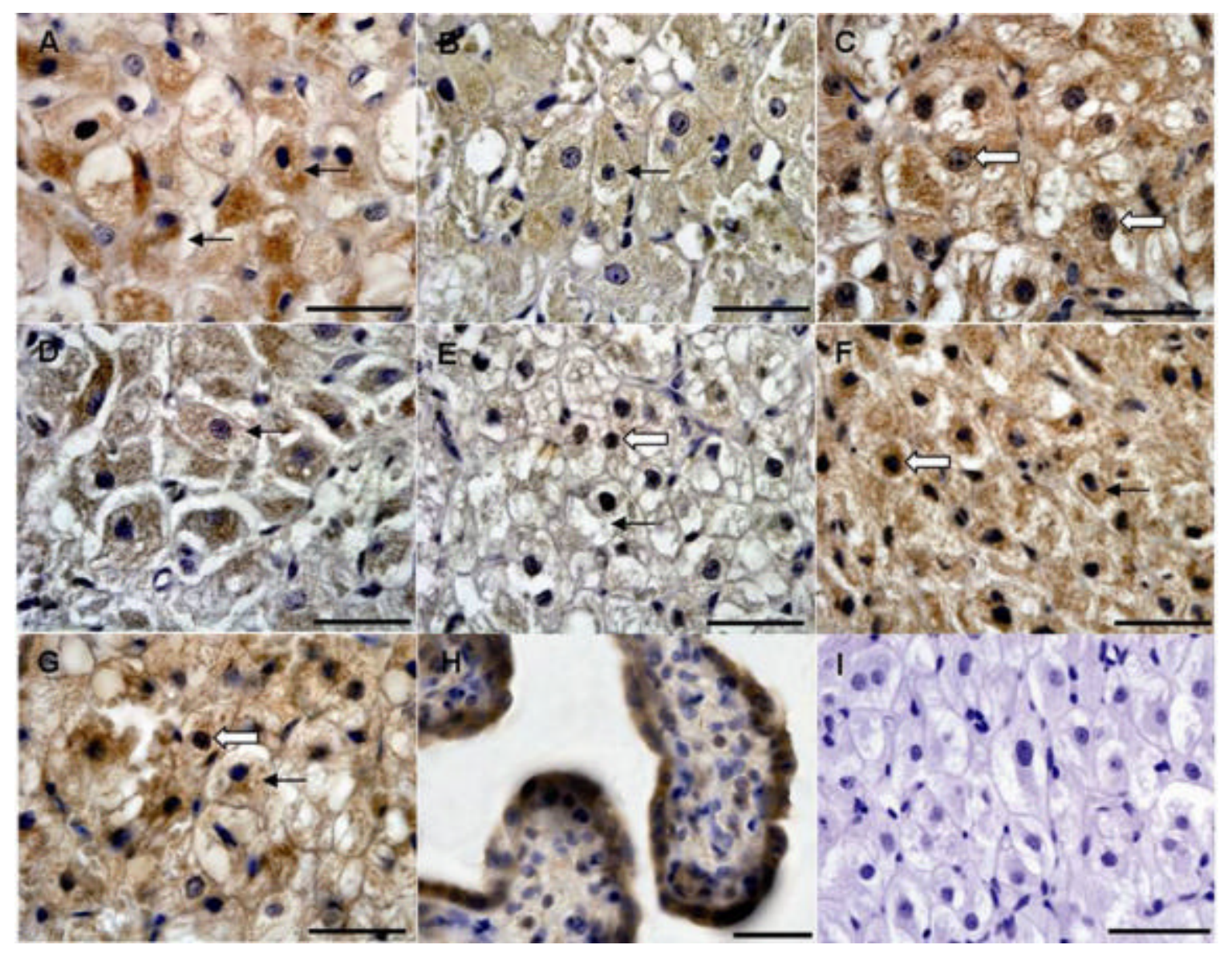


Figura 5 - Imunolocalização de GLUT1 no corpo lúteo canino ao longo do diestro. (A, B e C) Dias 10, 20 e 30: observa-se intensa reação no meio intracelular (coloração marrom) de células luteínicas, endoteliais e estromais. (D, E, F e G) Dias 40, 50, 60 e 70: a intensidade da reação diminui à medida que o diestro avança. (H) Placenta humana: controle positivo. (I) Dia 20: controle negativo. Barras $=20 \mu \mathrm{m}$

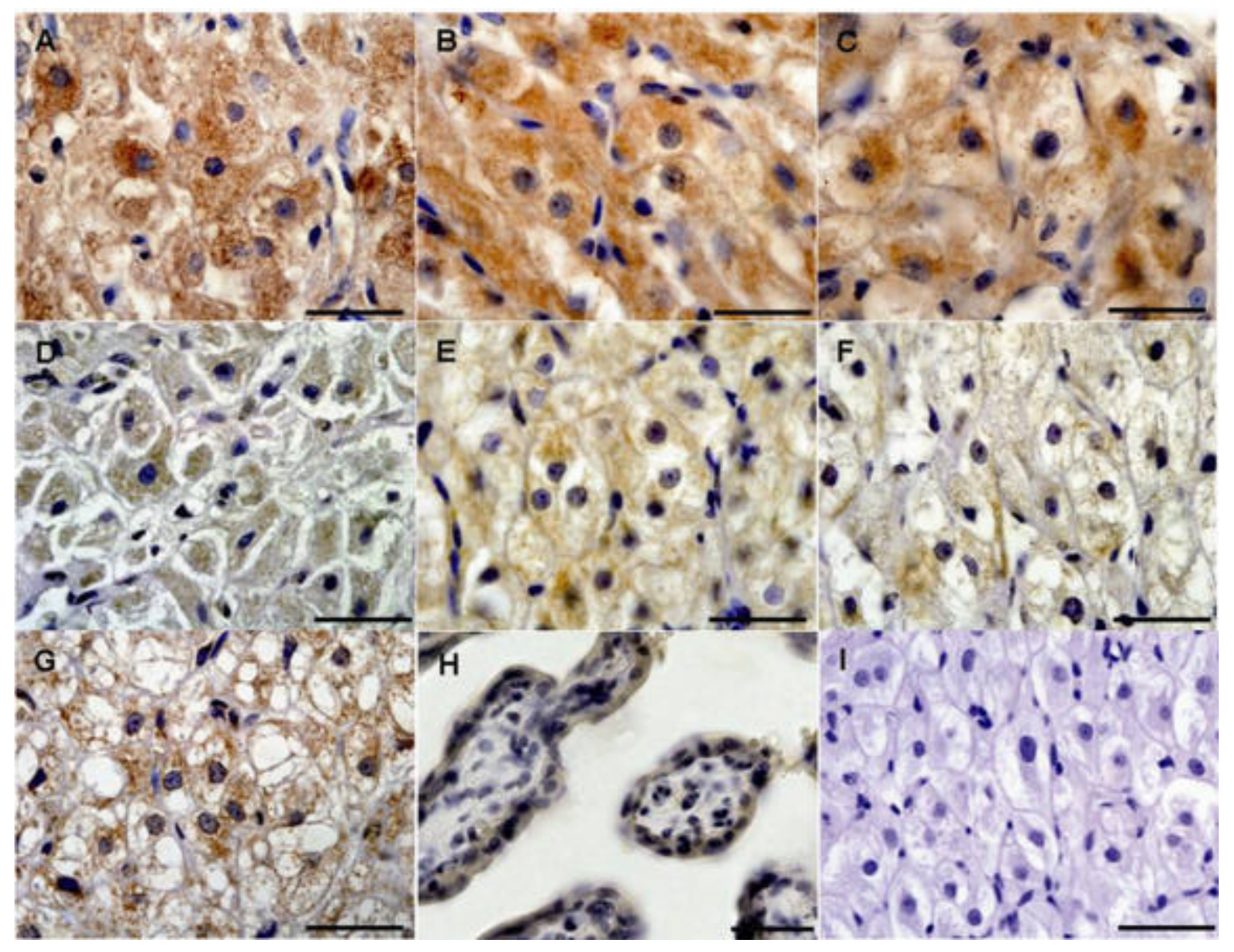


Figura 6 - Imunolocalização de GLUT4 no corpo lúteo canino ao longo do diestro. (A, B e C) Dias 10, 20 e 30: observa-se intensa reação no meio intracelular (coloração marrom) de células luteínicas, endoteliais e estromais. (D, E, F e G) Dias 40, 50, 60 e 70: a intensidade da reação diminui à medida que o diestro avança. (H) Músculo esquelético de camundongo: controle positivo. (I) Dia 20: controle negativo. Barras $=20 \mu \mathrm{m}$

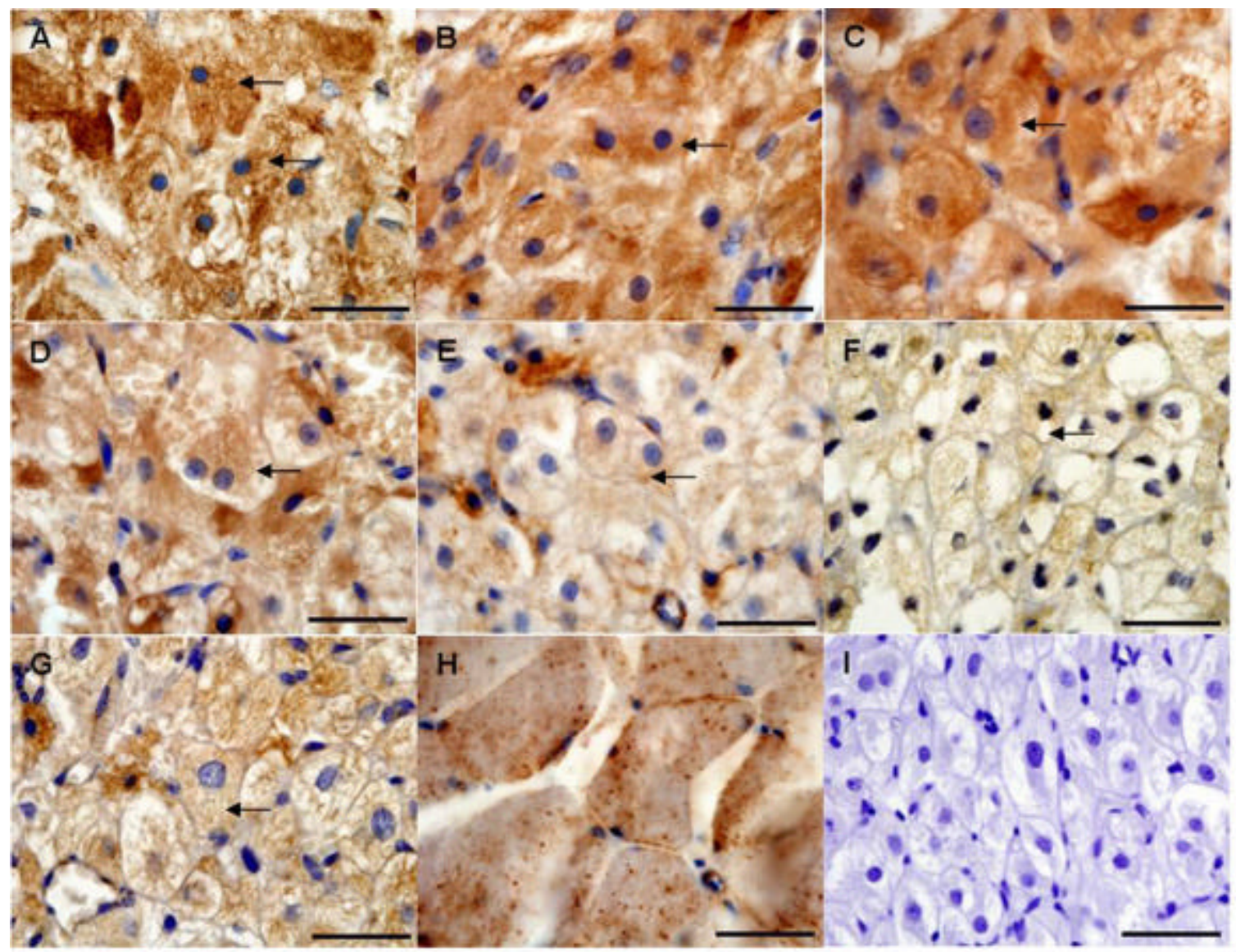




\subsection{EXPRESSÃO QUANTITATIVA DE HIF1A, GLUT1 E GLUT4 NO CORPO LÚTEO CANINO AO LONGO DO DIESTRO}

As proteínas do HIF1A, GLUT1 e GLUT4 demonstraram bandas específicas a 100, 55 e $45 \mathrm{kDa}$, respectivamente (Figuras 7A, 8A e 8C). Baseando-se na intensidade das bandas, após a normalização com as bandas específicas da actina,beta (ACTB), observou-se que houve efeito de tempo na expressão protéica de HIF1A ( $p<0,0001)$, GLUT1 (p = 0,04) e GLUT4 ( $\mathrm{p}=0,01)$. O HIF1A apresentou os maiores valores nos dias 30 e 60 após a ovulação (Figura 7B; p<0,05). A expressão de GLUT1 foi maior no dia 20 após a ovulação, diminuiu no dia 30 e apresentou uma tendência de aumento no dia 40, mas manteve-se constante até o final do diestro (Figura 8B). O GLUT4 foi mais expresso no dia 30 após a ovulação, diminuindo gradativamente até o dia 50, aumentando novamente no dia 60 após a ovulação (Figura 8D).

Figura 7 - Expressão protéica de $\operatorname{HIF} 1 \mathrm{~A}$ (A, B) no corpo lúteo canino ao longo do diestro. As imagens de eletroforese representam três experimentos independentes. As proteínas totais isoladas de homogenatos de tecido luteínico foram detectadas com anticorpo específico e normalizadas com a expressão de actina,beta (ACTB). Os dados são apresentados como média \pm DP. Barras com letras diferentes: $\mathrm{p}<0,05$

A

HIF1A

ACTB

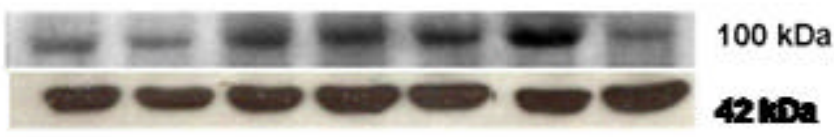

B

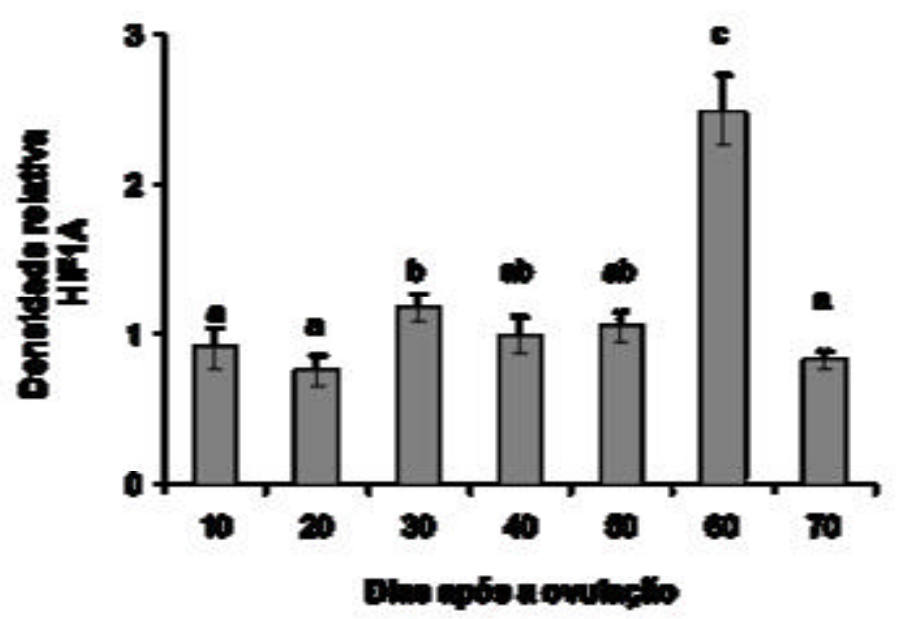


Figura 8 - Expressão protéica de GLUT1 (A e B) e GLUT4 (C e D) no corpo lúteo canino ao longo do diestro. As imagens de eletroforese representam três experimentos independentes. As proteínas totais isoladas de homogenatos de tecido luteínico foram detectadas com anticorpos específicos e normalizadas com a expressão de actina,beta (ACTB). Os dados são apresentados como média \pm DP. Barras com letras diferentes: $\mathrm{p}<0,05$

A

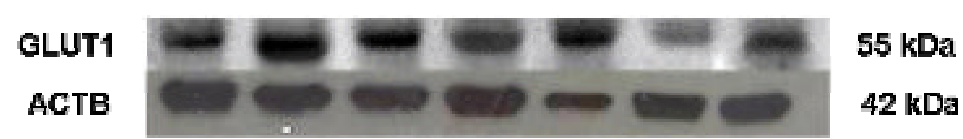

B

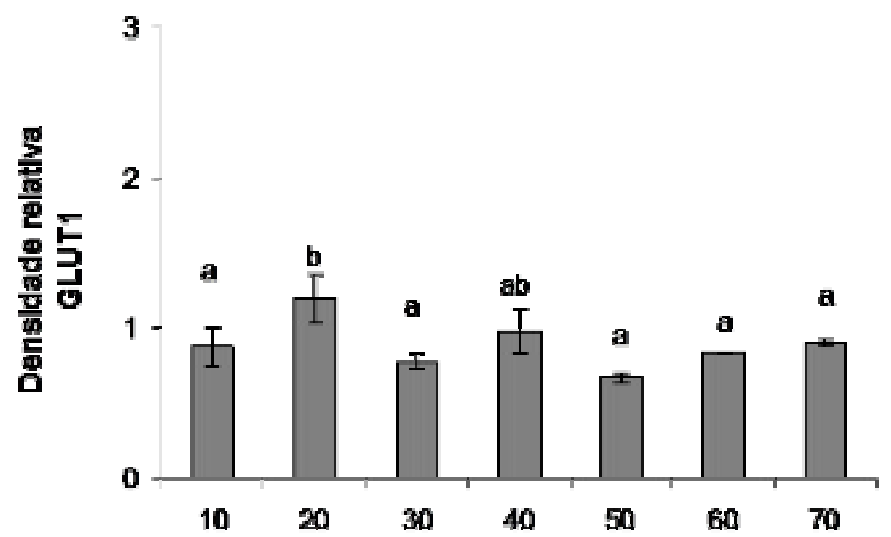

Dias após a ovukação

c

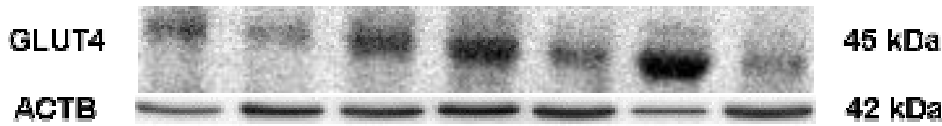

D

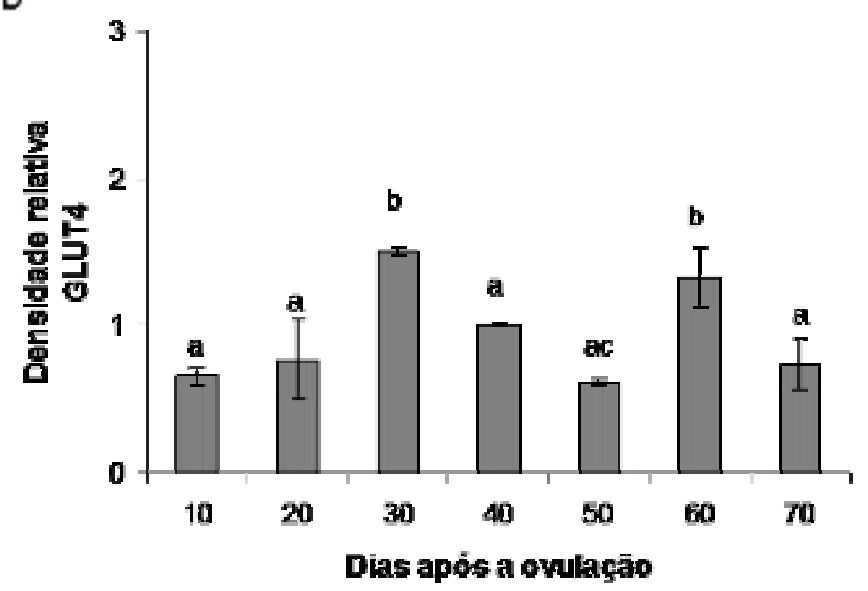


5.5 EXPRESSÃO GÊNICA DE HIF1A, SLC2A1/GLUT1, SLC2A4/GLUT4, VEGFA, FLT1 E KDR NO CORPO LÚTEO CANINO AO LONGO DO DIESTRO

A expressão do RNAm de HIF1A, SLC2A1, SLC2A4, VEGFA, FLT1 e KDR pôde ser detectada durante todo o curso do diestro por PCR em tempo real (Figura 9).

Houve efeito de tempo ( $\mathrm{p}<0,0001$ ) no que concerne a expressão de HIF1A, com um aumento observado no dia 20 após a ovulação, seguido por diminuição no dia 40, tornando a aumentar no dia 50 e a diminuir no dia 70 após a ovulação (Figura 9A). A expressão do RNAm dos transportadores de glicose, $S L C 2 A 1$ e $S L C 2 A 4$, foi regulada diferencialmente durante o diestro, demonstrando o efeito de tempo $(\mathrm{p}=0,002)$, com concomitante aumento nos dias 20 e 50 após a ovulação e diminuição no dia 40 (Figuras 9B e 9C). Observou-se efeito de tempo também na expressão de VEGFA, FLT1 e KDR $(\mathrm{p}=0,002)$. O VEGFA e o FLT1 apresentaram maior expressão entre os dias 20 e 60 após a ovulação, com concomitante diminuição no dia 40 (Figuras 9D e 9E), enquanto a expressão do $K D R$ apresentou maior expressão nos dias 20 e 40 após a ovulação (Figura 9F). 
Figura 9 - Expressão gênica de $\operatorname{HIF1A}$ (A), SLC2A1 (B), SLC2A4 (C), VEGFA (D), FLT1 (E) e KDR (F) no corpo lúteo de cadelas ao longo do diestro (dias 10 a 70 após a ovulação). Dados representados por média \pm desvio padrão da expressão relativa do gene $(n=3-4$ animais/grupo). Barras com letras e asteriscos indicam diferença significativa $(\mathrm{p}<0,05)$
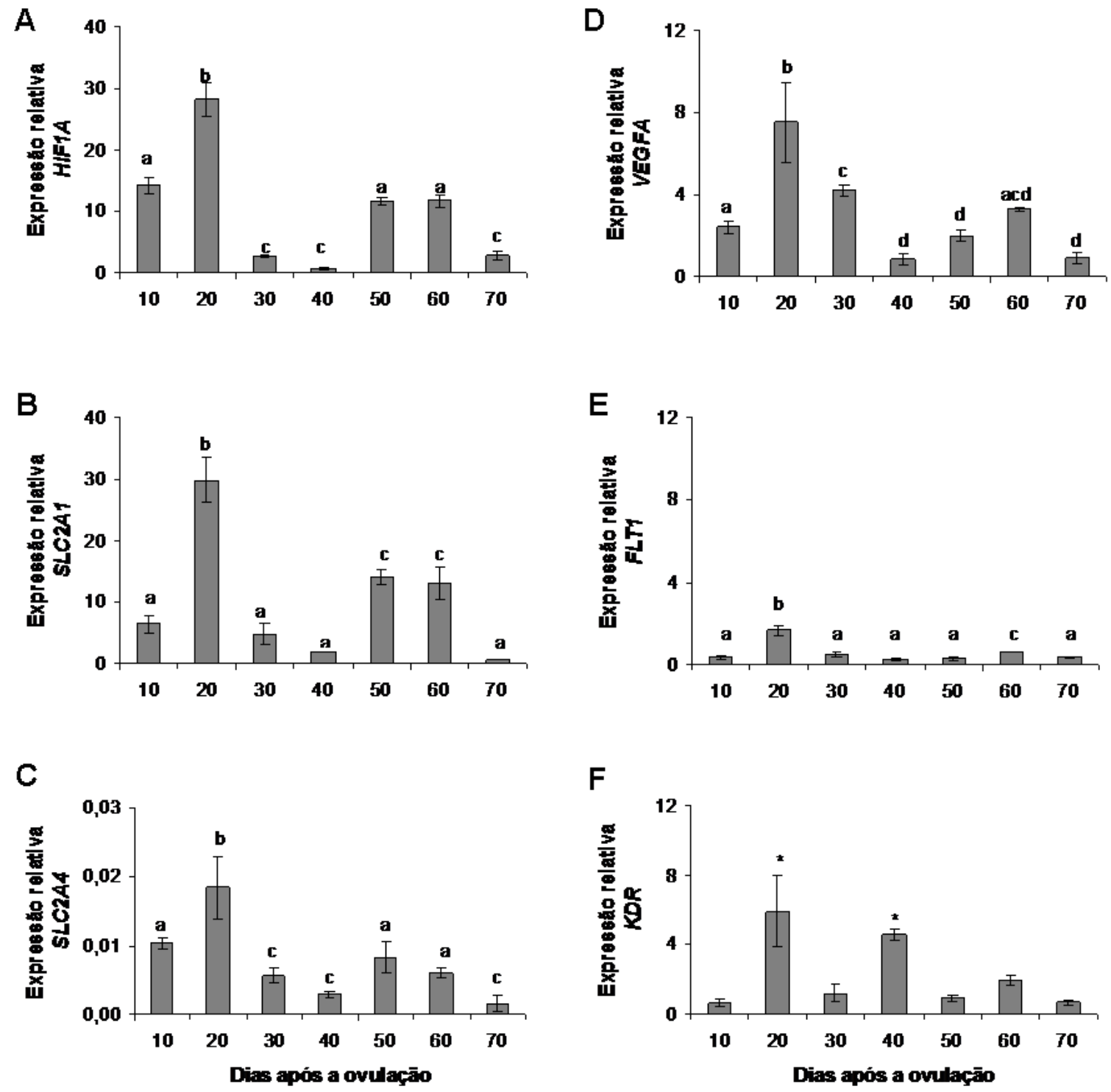


\subsection{CORRELAÇÃO ENTRE A EXPRESSÃO PROTÉICA DE HIF1A, GLUT1 E GLUT4 E GÊNICA DE HIF1A, SLC2A1, SLC2A4, VEGFA, FLT1 E KDR E AS CONCENTRAÇÕES DE PROGESTERONA E 17ß-ESTRADIOL}

As análises de correlação entre a expressão protéica e os perfis de progesterona e 17ßestradiol detectaram associações positivas e negativas no diestro como um todo ou em períodos específicos, denominados de primeira metade, na qual a progesterona é o hormônio dominante e de segunda metade, regida pelas flutuações de 17ß-estradiol.

A expressão da proteína do HIF1A foi correlacionada negativamente com a produção de progesterona na primeira metade do diestro $(r=-0,77 ; \mathrm{p}=0,02)$, enquanto a de GLUT1 foi positivamente correlacionada no mesmo período $(\mathrm{r}=0,86 ; \mathrm{p}=0,005)$. No entanto, não foi observada correlação entre a expressão de GLUT4 e a produção hormonal, nem entre aquela e expressão de HIF1A $(p>0,05)$.

As expressões de todos os genes investigados apresentaram correlação positiva com a progesterona na primeira metade do diestro (Tabela 2). A expressão de $S L C 2 A 4$, além de ser positivamente correlacionada com a progesterona, apresentou correlação negativa com as concentrações de 17ß-estradiol na segunda metade do diestro. Quando as expressões gênicas de SLC2A1, SLC2A4, VEGFA, FLT1 e KDR foram confrontadas com a expressão de HIF1A, observou-se que as mesmas encontram-se positivamente correlacionadas, à exceção do $K D R$ ( $p>0,05)$. Quando a expressão gênica foi confrontada com a protéica, observou-se correlação negativa entre o gene e a proteína do HIF1A $(\mathrm{r}=-0,86 ; \mathrm{p}=0,005)$ e positiva entre o GLUT1 e o SLC2A1 ( $\mathrm{r}=0,83 ; \mathrm{p}=0,009)$. Não foi observada correlação entre a expressão protéica e gênica do GLUT4 ( $\mathrm{p}>0,05)$. 
Tabela 2 - Coeficientes de correlação entre a expressão de HIF1A, SLC2A1, SLC2A4 e sistema VEGF e a produção de progesterona e 17ß-estradiol no corpo lúteo canino ao longo do diestro

\begin{tabular}{cccc}
\hline Variáveis correlacionadas & r de Pearson & Valor de P \\
\hline HIF1A & 0,78 & $0,03^{*}$ \\
SLC2A1 & 0,79 & $0,03^{*}$ \\
P4 vs & SLC2A4 & 0,82 & $0,02^{*}$ \\
& VEGFA & 0,85 & $0,01^{*}$ \\
& FLT1 & 0,90 & $0,005^{*}$ \\
& KDR & 0,76 & $0,04^{*}$ \\
\hline E2 vs & SLC2A4 & $-0,91$ & $0,01^{* *}$ \\
\hline \multirow{2}{*}{ HIF1A vs } & SLC2A1 & 0,93 & $0,002^{* * *}$ \\
& SLC2A4 & 0,98 & $<0,001^{* * *}$ \\
& VEGF & 0,98 & $0,03^{* * *}$ \\
& FLT1 & 0,84 & $0,01^{* * *}$ \\
\hline VEGFA & SLC2A4 & 0,90 & $0,005^{* * *}$ \\
\hline \multirow{2}{*}{ SLC2A1 } & VEGF & 0,84 & $0,001^{* * *}$ \\
& FLT1 & 0,83 & $0,007^{* * *}$ \\
\hline \multirow{2}{*}{ FLA } & VEGF & 0,85 & $0,01^{* * *}$ \\
& FLT1 & 0,83 & $0,01^{* * *}$ \\
\hline
\end{tabular}

* Correlatos na primeira metade do diestro

* Correlatos na segunda metade do diestro

${ }^{\star *}$ Correlatos ao longo do diestro 


\subsection{CARACTERIZAÇÃO MORFOLÓGICA DAS CÉLULAS LUTEÍNICAS CANINAS}

Células luteínicas, obtidas de experimentos independentes, demonstraram comportamento semelhante no decorrer do cultivo. As mesmas aderiram à placa de cultivo após 12-24 horas do início do experimento e após 48 - 72 horas, formaram pequenos agrupamentos, apresentando morfologia do tipo fibroblastóide e/ou alongada. Dentro de 5-7 dias, desenvolveu-se uma monocamada celular confluente $(80-90 \%)$, cujas células caracterizavam-se pelo formato poligonal (estrelado), núcleo arredondado e numerosas inclusões citoplasmáticas granulares (Figura 10).

Figura 10 - Cultivo primário de células luteínicas de cadelas. (A) Células em processo de adesão à placa de petri após 12 - 24 h. (B) Agrupamento de células luteínicas formados após 48 - 72 h de cultivo. (C) Monocamada celular confluente de células luteínicas após $5-7$ dias. Barra $=50 \mu \mathrm{m}$. (D) Fotomicrografia de células luteínicas caninas demonstrando o formato poligonal característico, grânulos e vacúolos de lipídeos (a) e núcleo (b). Barra $=20 \mu \mathrm{m}$
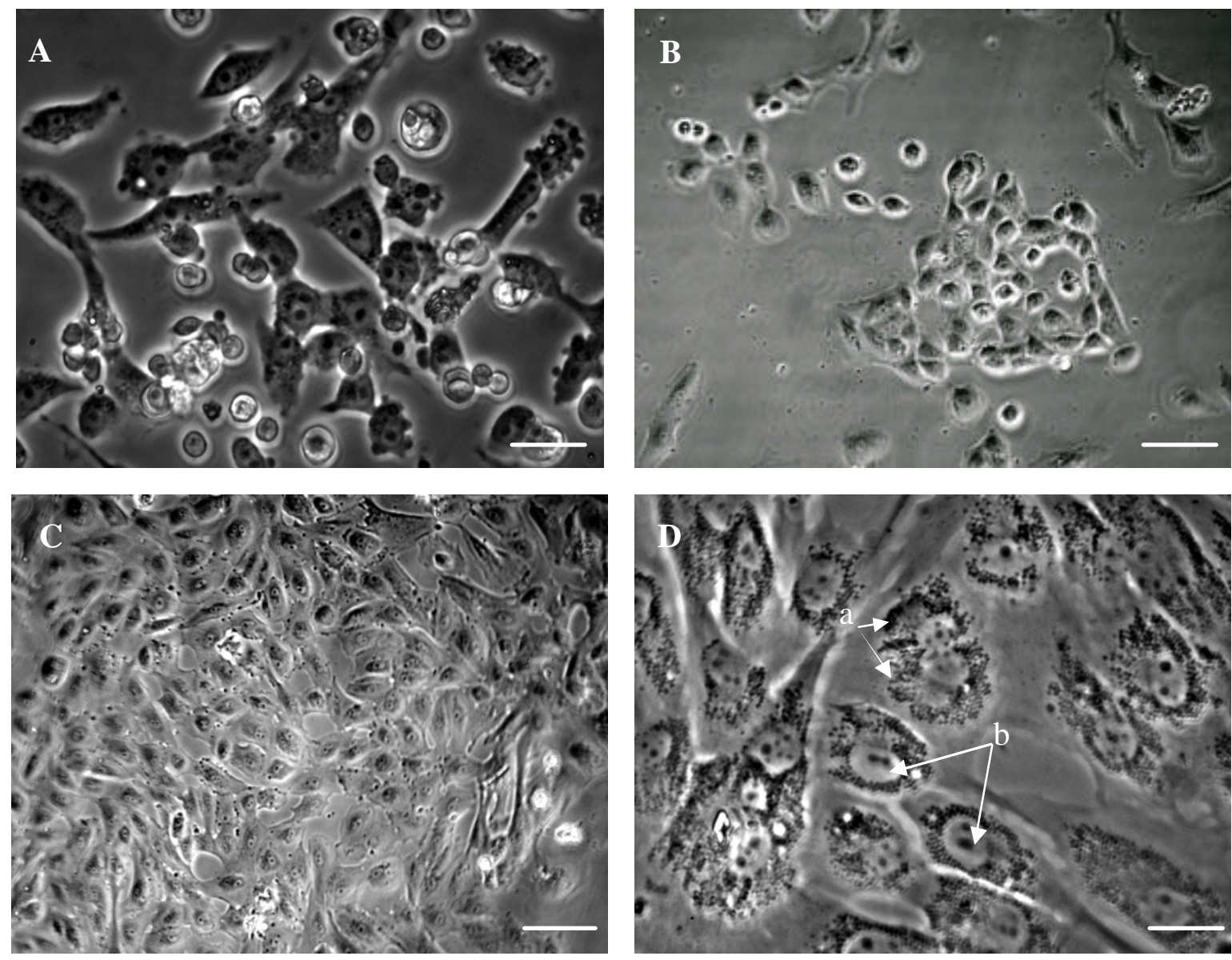


\subsection{EFEITO DA HIPÓXIA NA PRODUÇÃO DE PROGESTERONA E 17?-ESTRADIOL DAS CÉLULAS LUTEÍNICAS CANINAS}

Para verificar se a hipóxia afeta a esteroidogênese no corpo lúteo canino, células luteínicas foram cultivadas sem (grupo controle) e com $\mathrm{CoCl} 2$ a $500 \mu \mathrm{M}$ (grupo hipóxico) por 24 horas. Observou-se efeito inibitório da hipóxia tanto na concentração de progesterona ( $\mathrm{p}=0,01$; Figura 11A) quanto na de 17B-estradiol $(\mathrm{p}=0,03$; Figura 11B), quando as concentrações foram, respectivamente, 5 e 4 vezes menores no grupo tratado em relação ao controle.

Figura 11 - Efeito da hipóxia (induzida por CoCl2 a $500 \mu \mathrm{M}$ ) na produção de progesterona (ng/ml; A) e de 17ßestradiol (pg/ml; B) em células luteínicas ( $\mathrm{n}=3$ animais / grupo). Os dados foram representados por média \pm desvio padrão. Asteriscos representam diferença significativa $(\mathrm{p}<0,05)$
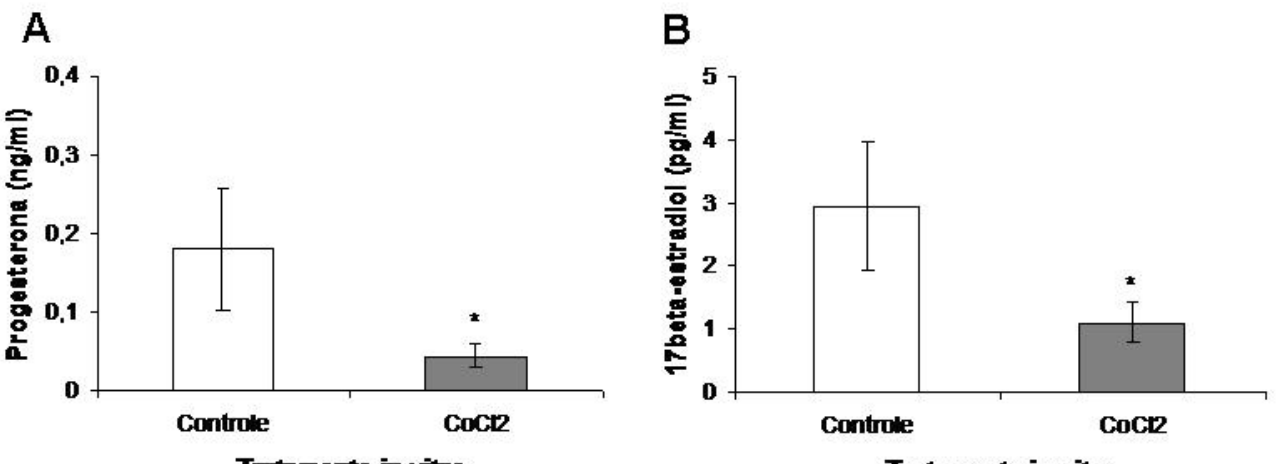
5.9 EFEITO DA HIPÓXIA NA EXPRESSÃO GÊNICA DE HIF1A, SLC2A1, SLC2A4 E VEGFA NAS CÉLULAS LUTEÍNICAS CANINAS

A expressão gênica de $H I F 1 A$, SLC2A1, SLC2A4 e VEGFA foram detectadas em todos os períodos investigados (dias 10, 30 e 60 após a ovulação; Figura 11). Para verificar o efeito da hipóxia na expressão dos genes acima citados, células luteínicas foram cultivadas sem (grupo controle) e com CoCl2 a $500 \mu \mathrm{M}$ (grupo hipóxico) por 24 horas.

Não houve efeito de tempo na expressão de SLC2A1, SLC2A4 e VEGFA (p > 0,05), porém, observourse tendência de aumento entre os dias 10 e 60 na expressão do $\operatorname{HIF} 1 A$ (p = 0,057). Houve efeito da hipóxia (mimetizada pelo $\mathrm{CoCl} 2$ a $500 \mu \mathrm{M}$ ) na expressão do RNAm de HIF1A ( $\mathrm{p}=0,002), \operatorname{SLC} 2 A 1(\mathrm{p}=0,02)$, SLC2A4 ( $\mathrm{p}=0,01)$ e VEGFA $(\mathrm{p}=0,04)$, com aumento significativo de expressão em relação ao respectivo controle. A interação entre o tempo (dias 10, 30 e 60 após a ovulação) e o tratamento in vitro ( 0 ou $500 \mu \mathrm{M}$ de $\mathrm{CoCl} 2)$ foi significativa $(\mathrm{p}<0,05)$ para a expressão de HIF1A e SLC2A4 nos dias 10, 30 e 60 após a ovulação (Figuras 12A e 12B) e para o VEGFA nos dias 10 e 60 (p = 0,04 e 0,05; Figura 12D), enquanto para a expressão de $S L C 2 A 1$ houve interação apenas no dia 60 após a ovulação ( $\mathrm{p}=0,01$; Figura 12C). 
Figura 12 - Efeito da hipóxia (induzida por $\mathrm{CoCl} 2$ a $500 \mu \mathrm{M}$ ) na expressão gênica de HIF1A (A), SLC2A4 (B), SLC2A1 (C) e VEGFA (D) em células luteínicas nos dias 10, 30 e 60 após a ovulação (n = 3 animais / grupo). Os dados foram transformados em raiz quadrada e representados por média \pm desvio padrão. Asteriscos representam diferença significativa $(\mathrm{p}<$ $0,05)$
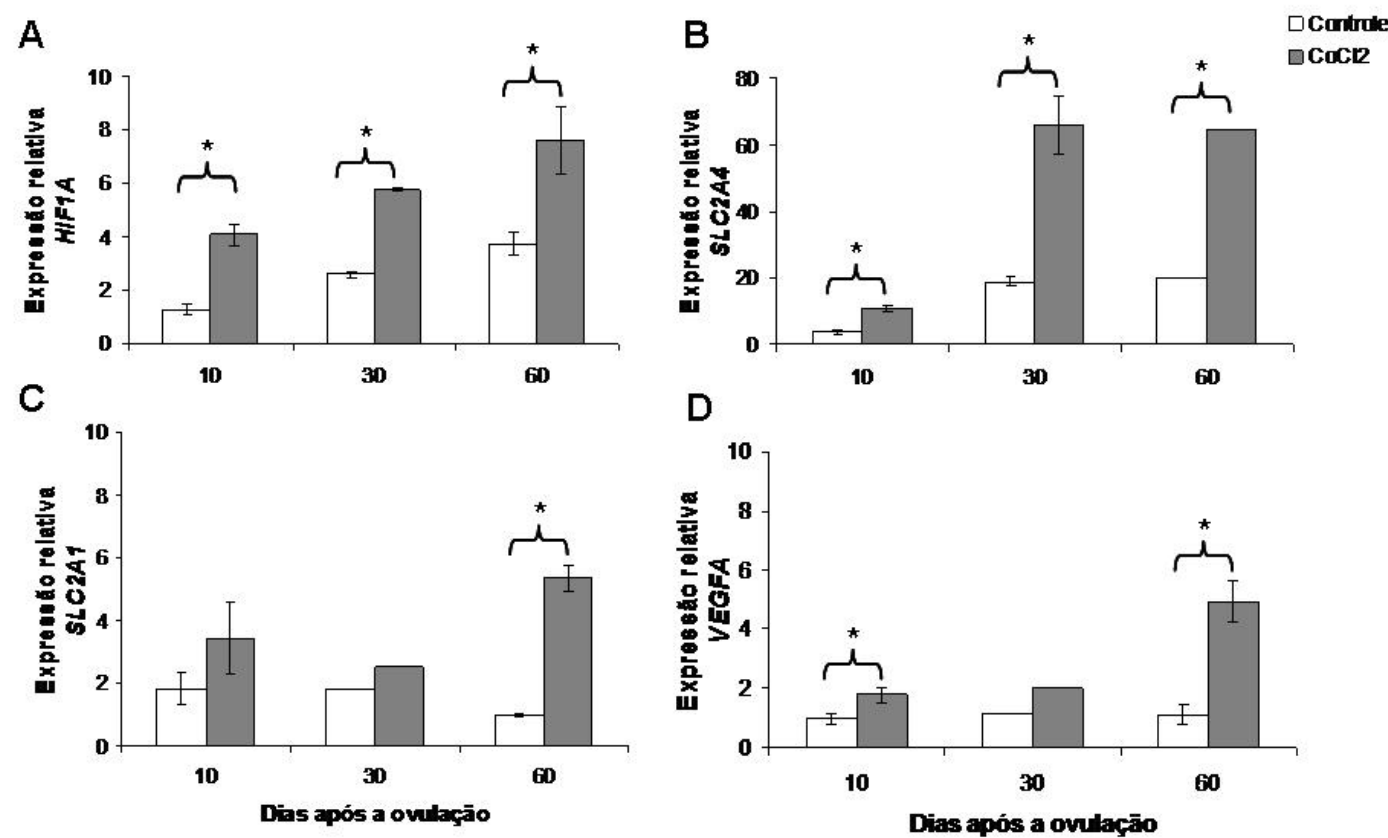


\section{DISCUSSÃO}

No presente trabalho, a expressão gênica e protéica do fator indutível por hipóxia HIF1A foi observada no CL canino, a qual ocorreu de maneira tempo-dependente e mostrou ser relacionada à expressão de seus alvos clássicos: o fator de crescimento endotelial vascular (VEGFA) e os transportadores de glicose, GLUT1 (gene SLC2A1) e GLUT4 (gene SLC2A4), e à produção hormonal, especialmente a de progesterona. Além disso, observaram-se interrelações importantes entre a expressão gênica e protéica e os perfis plasmáticos de progesterona e 17ß-estradiol, o que reflete diretamente a função do corpo lúteo durante o diestro (PAPA; HOFFMANN, 2011). Ao mesmo tempo, foram discutidos os efeitos da hipóxia sobre a esteroidogênese e sobre a expressão gênica dos fatores acima citados nas células luteínicas caninas, sugerindo a possível participação da hipóxia, via expressão do HIF1A, na regulação da função luteínica de cadelas não prenhes, especialmente no que diz respeito à fase de regressão.

Através de análise por imuno-histoquímica e western blotting, verificou-se que a proteína HIF1A está presente no citoplasma das células luteínicas ao longo do diestro, com maior expressão na metade (dia 30 po) e no final (dia 60) do mesmo, quando também foi observado sinal nuclear mais intenso. As mudanças na expressão gênica e protéica do HIF1A, ao longo do diestro, foram correlacionadas negativamente entre si. O primeiro aumento na expressão do RNAm do HIF1A foi observado no dia 20 po., período no qual o corpo lúteo encontra-se no ápice da produção de progesterona e o aumento dessa expressão foi acompanhado pela elevação gênica de VEGFA, SLC2A1 e SLC2A4. No dia 30, no entanto, com a diminuição da produção de progesterona, o que caracteriza o início da luteólise funcional (SONNACK, 2009), ocorre a diminuição da expressão gênica tanto do HIF1A quanto dos outros fatores. Paralelo a essa diminuição, foi observado um aumento significativo da expressão da proteína HIF1A e também a presença da mesma no núcleo das células luteínicas. Embora nesse período seja observado o início da perda de função, observou-se que as células luteínicas produzem $17 ß$-estradiol, cujas concentrações encontram-se em elevação até o dia 40, quando alcança a concentração máxima. Nos dias 40 e 50 po, a expressão protéica do HIF1A permanece constante. No entanto, sua expressão gênica diminui no dia 40, mas apresenta um segundo aumento no dia 50 po, o qual antecede o aumento mais expressivo da proteína HIF1A no dia 60 po, apontando para um momento da vida útil do corpo lúteo, no 
qual a produção hormonal não é mais necessária e coincide com o início da luteólise estrutural na cadela (SONNACK, 2009).

O HIF1 é um fator transcricional, constituído pelas subunidades A e B. que auxilia no restabelecimento da homeostase de oxigênio a nível celular, local e sistêmico. Sua expressão é fortemente regulada a nível protéico, principalmente pela proteólise dependente de oxigênio de sua subunidade A, a qual, sob normóxia é degradada e, sob condições de privação de oxigênio, é estabilizada por uma via de ativação que envolve a translocação do citoplasma para o núcleo, a dimerização com a subunidade HIF1B, o recrutamento de coativadores transcricionais e subsequente ligação aos elementos responsivos à hipóxia presentes nos genes-alvo (STROKA et al., 2001). Dessa forma, o contéudo protéico de HIF1A é mais relacionado às condições de oxigênio do que a expressão gênica, indicando uma condição hipóxica no tecido (NISHIMURA; OKUDA, 2010). Apesar da expressão do HIF1A estar associada à hipóxia, a presença nuclear da proteína HIF1A foi observada em tecidos distintos (cérebro, rins, fígado e coração) sob condições normóxicas, sugerindo que mesmo sob tensões fisiológicas de oxigênio, o HIF1A deve estar presente para garantir a indução basal de genes necessários para prover as demandas metabólicas celulares (STROKA et al., 2001). Nossos achados reforçam esse conceito, sugerindo que o HIF1A é expresso no corpo líteo canino possivelmente para induzir a expressão de fatores como o VEGFA e os GLUTs, garantindo o aporte sanguíneo e nutricional necessário, especialmente na primeira metade do diestro.

O HIF1A é reconhecido como o principal indutor angiogênico em vários tecidos (MARTI, 2005) e o VEGFA como o principal fator angiogênico ovariano, por modular funções importantes como o desenvolvimento folicular, a formação do corpo lúteo e a fertilidade, através da interação com seus receptores FLT1 e KDR (QIU et al., 2012). Nas células luteínicas caninas, a expressão gênica do VEGFA e do FLT1 foi maior nos dias 20 e 60 po, com diminuição no dia 40, paralelas à maior e menor expressão do HIFlA, respectivamente, enquanto o KDR apresentou maior expressão nos dias 20 e 40 po. A expressão protéica do sistema VEGF no CL canino foi previamente descrita (MARIANI et al., 2006) e embora a expressão do VEGFA diminua no dia 40 po e a de seus receptores pareça ser constante, em sua maior parte, acompanha o padrão da expressão gênica demonstrado neste estudo. A relação entre a hipóxia e o aumento da expressão do $V E G F A$, via indução do HIF1A, foi também observada no corpo lúteo de bovinos (SEMENZA, 2003; NISHIMURA; OKUDA, 2010; ZHANG, Z.; YIN; WANG, 2011) e parece estar diretamente envolvida em sua formação. Essa relação ocorre devido à ligação do $H I F 1 A$ ao elemento responsivo a hipóxia presente na região promotora do VEGFA. Quando essa ligação é estabelecida, tanto a 
transcrição quanto a estabilidade do RNAm do VEGFA é aumentada (CAO et al., 1996; LEVY, A. P.; LEVY; GOLDBERG, 1996) e uma clara conexão entre hipóxia, HIF1A, VEGFA e capilaridade luteínica pode ser visualizada (ZHANG, Z.; YIN; WANG, 2011). Nas células luteínicas caninas, o maior aumento da expressão do VEGFA e do FLT1 foi visualiza do no momento de maior concentração de progesterona plasmática, enquanto o KDR foi mais expresso no dia 40, quando das maiores concentrações de 17ß-estradiol. Além de seu conhecido papel primordial na angiogênese, o VEGFA é considerado um fator luteotrófico em bovinos, uma vez que está apto a induzir a expressão da proteína esteroidogênica regulatória aguda (STAR), responsável por transportar colesterol para o interior da mitocôndria (STOCCO, 2001). Na mitocôndria, a enzima CY11A1 (também conhecida por P450scc) converte o colesterol em pregnenolona (P5), a qual é convertida pela enzima 3ßhidroxiesteróide-dehidrogenase (HSD3B) a progesterona (SIMARD et al., 2005). No corpo lúteo de cadelas, tanto a expressão gênica quanto a protéica da STAR e da HSD3B diminuíram durante a segunda metade do diestro, apresentando os níveis mais baixos no dia 65 após a ovulação (KOWALEWSKI et al., 2006a; KOWALEWSKI; HOFFMANN, 2008), período em que foi observada a maior expressão da proteína HIF1A, apontando para uma possível inter-relação funcional entre esta e a produção de progesterona.

Como a glicose é considerada uma fonte de energia importante para a atividade ovariana (CHASE et al., 1992) e o passo limitante para o seu metabolismo consiste na sua entrada para o meio intracelular, analisou-se também a expressão gênica e protéica dos transportadores de glicose, GLUT1 e GLUT4 nas células luteínicas. Tanto a expressão gênica do $S L C 2 A 1$ quanto do SLCA4 ocorre de maneira tempo-dependente, apresentando a maior expressão nos dias 20 e 50 e menores no dia 40 po, acompanhando a expressão gênica de HIFlA. O transporte de glicose é estimulado rapidamente sob condições de hipóxia e a resposta é mediada pelo aumento da atividade dos transportadores de glicose. A expressão e atividade da captação de glicose mediada pelos GLUTs está associada ao status energético da célula de tal forma que a inibição da fosforilação oxidativa resultante da exposição à hipóxia, leva a indução da captação de glicose, via ligação direta do HIF1A ao elemento responsivo à hipóxia presentes na região promotora dos genes SLC2A, pelos seguintes mecanismos (BEHROOZ; ISMAILBEIGI, 1999; ZHANG, J. Z.; BEHROOZ; ISMAIL-BEIGI, 1999): promove a translocação tanto de GLUT1 quanto de GLUT4 das vesículas intracelulares para a membrana plasmática e a ativação de transportadores pré-existentes na membrana (YOUNG et al., 1997). Uma exposição mais prolongada à hipóxia resulta no aumento da transcrição do gene $S L C 2 A 1$, com 
pouco ou nenhum efeito em outros genes $S L C 2 A$, mediado ou pelo aumento da transcrição do SLC2A1 em resposta à redução da concentração de oxigênio per se, atuando através da via de sinalização de hipóxia ou pela transcrição secundária do SLC2A1 associado à inibição da fosforilação oxidativa pela hipóxia (ZHANG, J. Z.; BEHROOZ; ISMAIL-BEIGI, 1999).

A expressão do SLC2A1, além de ser correlacionada com o HIF1A, apresentou correlação positiva com a progesterona periférica, sendo mais alta no dia 20 po. Em células endometriais, a progesterona regula diretamente a expressão de $S L C 2 A 1$ através de seu receptor (FROLOVA et al., 2009; KIM; MOLEY, 2009), ativando a via de sinalização Akt/PKA/PRKAA e aumentando a expressão e translocação de GLUT1 (KIM; MOLEY, 2009). Por outro lado, estrógenos exercem regulação negativa sobre SLC2A1/GLUT1 quando testado sozinho ou em combinação com progesterona e o bloqueio do receptor de estrógenos 1 (ESR1 ou ERa) é capaz de reverter os efeitos dos estrógenos (KIM; MOLEY, 2009). Trazendo esses dados para o contexto do corpo lúteo canino, é possível que a tríade hipóxiaHIF1A-progesterona atue da mesma maneira aumentando a expressão de SLC2A1/GLUT1 através de seu receptor (HOFFMANN et al., 2004; PAPA; HOFFMANN, 2011) com o intuito de aumentar a disponibilidade de glicose, no sentido de manter a sua própria produção, sustentando o conceito deste hormônio ser um importante fator luteotrófico local.

Um achado importante do presente estudo foi a expressão do GLUT4/SLC2A4 no corpo lúteo canino. O GLUT4 é um transportador que atua sob a influência da insulina, encontrado no músculo esquelético, músculo cardíaco e células adiposas(JOHNSON, 2008) . A expressão do SLC2A4 foi correlacionada diretamente com a progesterona e com a expressão de HIF1A na primeira metade do diestro e negativamente com o 17ß-estradiol na segunda metade. Em alguns tecidos, como o cérebro de rato, o GLUT4 é restrito a áreas pequenas, as quais geralmente estão relacionadas com a localização anatômica do receptor de insulina (LIVINGSTONE; LYALL; GOULD, 1995; EL MESSARI et al., 1998), uma vez que a insulina, após ligar ao seu receptor, ativa uma via intracelular que culmina com a translocação do GLUT4 presente nas vesículas intracelulares para a membrana plasmática, aumentando a captação de glicose (ZHOU, L. et al., 1999). O receptor de insulina é expresso de maneira tempo-dependente pelas células luteínicas caninas e sua expressão é correlacionada positivamente com a expressão de $S L C 2 A 4(\mathrm{r}=0,89 ; \mathrm{p}=0,01)$ ao longo do diestro (SILVA, R. S., 2012), sugerindo uma possível participação da insulina na regulação da captação de glicose pelo GLUT4 no CL dessa espécie. 
A resistência à insulina é uma característica da gestação (JOHNSON, 2008) e é atribuída a progesterona e ao hormônio de crescimento $(\mathrm{GH})$, os quais estão presentes em concentrações similares em cadelas prenhes e não prenhes (EIGENMANN et al., 1983; BHATTI, 2006). No presente estudo, a hiperinsulinemia relativa foi calculada pela análise das relações insulina:glicose e insulina:glicose corrigida (PÖPPL et al., 2009; VERKEST et al., 2010) e a resistência insulínica, através dos índices HOMA2 (LEVY, J. C.; MATTHEWS; HERMANS, 1998) e HOMA (MATTHEWS et al., 1985). Embora nos animais analisados não tenha sido observada hiperinsulinemia relativa ou resistência à insulina, pois, embora os maiores índices tenham sido observados nos dias 10 e 40 após a ovulação, os mesmos encontram-se abaixo dos valores de referência. Esses momentos refletem os períodos em que as células luteínicas estão em plena produção de progesterona e de 17ß-estradiol, respectivamente., observando-se também as maiores concentrações de insulina.

O aumento nas concentrações de 17ß-estradiol associado à diminuição dos índices de sensibilidade à insulina, concomitantes com a diminuição da expressão de SLC2A4 no dia 40 após a ovulação, corrobora com relatos de várias condições caracterizadas por concentrações de estrógenos elevadas que também são acompanhadas por resistência insulínica, tais como gestação, diabetes gestacional e síndrome do ovário policístico (OKUNO et al., 1995; SOLOMON et al., 2001; KAAJA; GREER, 2005). A gestação afeta os mecanismos regulatórios da glicose de duas maneiras: no primeiro momento promove a resistência à insulina, a qual suprime o transporte intracelular de glicose (i.e. diminui a utilização da glicose), criando uma deficiência de energia intracelular relativa e aumentando as concentrações da glicose plasmática. Em situações extremas, pode-se desenvolver o diabetes mellitus gestacional. A progesterona, estradiol, hormônio de crescimento, lactogênio placentário e citocinas placentárias têm importante papel na resistência insulínica (BATISTA et al., 2005). Essa deficiência de insulina relativa permite a mobilização de ácidos graxos dos adipócitos e a troca da síntese hepática para cetogênese (FELDMAN; NELSON, 2004). A sensibilidade a insulina é reduzida para aproximadamente $43 \%$ durante a fase final da gestação de cadelas, devido a marcante resistência a insulina no músculo esquelético e adipócitos, enquanto a sensibilidade à insulina hepática não é alterada (JOHNSON, 2008). Mecanismos de controle complementares atuam para manter a homeostase da glicose; porém, a insulina é o regulador mais importante, controlando os metabolismos de carboidratos, proteínas e lipídios nos tecidos muscular, adiposo e fígado (ECKEL; GRUNDY; ZIMMET, 2005). No músculo e no tecido adiposo, o GLUT4 é predominantemente expresso (GOULD; HOLMAN, 1993) e é o passo limitante para a captação de glicose induzida pela insulina 
(REA; JAMES, 1997). A atividade dos receptores de estrógenos, ESR1 e ESR2, possuem efeitos distintos na captação de glicose; o ESR1 aumenta e o ESR2 reduz o SLC2A4, indicando participação do estrógeno na homeostase glicêmica (BARROS et al., 2006). As células luteínicas caninas, após estímulo insulínico no dia 40 após a ovulação, fase na qual as concentrações de $17 ß$-estradiol são maiores, diminuem a expressão tanto do SLC2A4 quanto do receptor de insulina (SILVA, R. S., 2012). O 17ß-estradiol tem a capacidade de modular a expressão gênica por meio da interação de seus receptores com outros fatores transcricionais (NILSSON et al., 2001), dentre eles o fator nuclear-?B (NFKB) (GALIEN; GARCIA, 1997; BISWAS et al., 2005), proposto como um importante inibidor da expressão do SLC2A4 (RUAN et al., 2002; SILVA, J. L. et al., 2005), por meio de mecanismos que incluem a degradação do fator transcricional, a competição por cofatores nucleares e/ou a interação direta entre o ER e o NFKB (GUZELOGLU-KAYISLI et al., 2008). Barros e colaboradores (BARROS et al., 2006) propuseram que a interação ESR1/NFKB impediria a ligação do NFKB à região promotora do $S L C 2 A 4$, diminuindo a ação inibitória desse fator. No CL canino, no dia 40 po, foi observado um aumento da expressão do NFKB (SILVA, R. S., 2012), e a diminuição de ESR1 (PAPA; HOFFMANN, 2011), sugerindo que os elevados níveis de $17 ß$-estradiol podem reprimir a expressão de $S L C 2 A 4$ no corpo lúteo canino via NFKB, assim predispondo esses animais à condição de resistência insulínica comumente observada no diestro, corroborando com os dados ex vivo obtidos no presente estudo.

O real significado do aumento do $17 ß$-estradiol no dia 40 po, que antecede os primeiros sinais da luteólise estrutural (SONNACK, 2009) precisa ser melhor investigado, uma vez que seu receptor nuclear (ESR1) possui regulação gênica e protéica ciclo-dependente (PAPA; HOFFMANN, 2011) e está envolvido na modulação da expressão do SLC2A4 (BARROS et al., 2006) e, consequentemente, na captação de glicose. Embora o aumento de $17 ß$-estradiol não tenha sido descrito por outros autores, parece plausível que isso ocorra no CL canino, uma vez que a aromatase P450 e o seu gene CYP19 também são regulados no diestro (PAPA; HOFFMANN, 2011).

Para verificar a relação entre hipóxia, esteroidogênese, angiogênese e captação de glicose, células luteínicas primárias foram isoladas e submetidas por 24 horas ao tratamento com cloreto de cobalto $(\mathrm{CoCl} 2)$, conhecido como um indutor químico de hipóxia (GRASSELLI et al., 2005).

A resposta frente ao estímulo hipóxico foi observado com o aumento significativo da expressão do RNAm do HIF1A, o que corrobora com estudos prévios realizados em corpo lúteo bovino sob as mesmas condições de cultivo (NISHIMURA; OKUDA, 2010; JIANG, Y. 
F. et al., 2011). A hipóxia também exerceu efeito estimulatório na expressão do mRNA do VEGFA e transportadores de glicose, SLC2A1 e $S L C 2 A 4$, o que corrobora com o que foi observado em placenta humana (HAYASHI et al., 2004) e cérebro de rato (ROYER et al., 2000) e em nosso modelo ex vivo. Esse evento reflete a adaptação do metabolismo de glicose nas células luteínicas caninas frente às condições hipóxicas e corrobora com a hipótese da expressão do HIF1A ser luteotrófica. Sob condições anaeróbicas, a glicose é metabolizada por glicólise para a produção de energia (Efeito Pasteur) (BERG; TYMOCZKO; STRYER, 2002). No processo de glicólise, numerosas enzimas participam e durante a resposta adaptativa a hipóxia, a expressão de genes que codificam enzimas glicolíticas aumenta (FIRTH et al., 1994; SEMENZA et al., 1996). Para manter a glicólise elevada, deve haver o aumento da captação de glicose, a qual é facilitada pelo aumento na expressão de $S L C 2 A 1 e$ SLC2A4 sob condições hipóxicas.

Por outro lado, foi observado efeito inibitório da hipóxia na produção de progesterona e de 17ß-estradiol nas células luteínicas. O efeito negativo da hipóxia sobre a produção de progesterona em células luteínicas bovinas foi associado à supressão da atividade enzimática e da expressão gênica de CY11A1 (NISHIMURA et al., 2006; NISHIMURA; OKUDA, 2010), STAR e HSD3B (JIANG, Y. F. et al., 2011), as quais são enzimas integrantes da cascata esteroidogênica.

O efeito inibitório da hipóxia na produção de 17ß-estradiol também foi observado em células da granulosa de suínos submetidas ao tratamento com $\mathrm{CoCl} 2$ (GRASSELLI et al., 2005), o qual, além de induzir a expressão de HIF1A, estimula a expressão de compostos reativos de oxigênio, tais como o peróxido de hidrogênio $\left(\mathrm{H}_{2} \mathrm{O}_{2}\right)$, suprimindo as defesas antioxidantes das células (CHANDEL et al., 1998). O aumento das concentrações de $\mathrm{H}_{2} \mathrm{O}_{2}$ também poderia explicar a diminuição na produção de estrógenos, por inibir a atividade da aromatase P450 (WINNETT; VAN HAGEN; SCHREY, 2003). A aromatase P450 é a enzima que converte androstenediona ou testosterona em estrógenos e, no corpo lúteo canino, seu gene CYP19 é expresso ao longo do diestro de maneira tempo-dependente, com os menores níveis no dia 5 e os maiores, no dia 35 após a ovulação (PAPA; HOFFMANN, 2011), seguindo o perfil de 17ß-estradiol. O efeito da hipóxia sobre a expressão das enzimas esteroidogênicas não foi analisado nesse estudo, porém, os nossos resultados sugerem que é provável que a hipóxia reduza a síntese de progesterona e de 17ß-estradiol via inibição da expressão das mesmas. 
A expressão gênica e protéica do HIF1A no corpo lúteo canino traz evidências da existência de um ambiente com baixas concentrações de oxigênio e da influência deste na função luteínica. Através dessas análises, observou-se que a resposta ex vivo difere da resposta in vitro, na qual a hipóxia, apesar de estimular a expressão do RNAm do HIF1A, $V E G F A, S L C 2 A 1$ e $S L C 2 A 4$, inibiu a produção tanto de progesterona quanto de $17 ß$-estradiol. No modelo ex vivo, a expressão gênica do HIF1A foi acompanhada tanto pela expressão dos fatores acima citados quanto pela produção de progesterona, na primeira metade do diestro e, na segunda metade, a qual é regida por flutuações do17ß-estradiol, houve aumento de sua expressão protéica, concomitante com a diminuição da expressão dos transportadores de glicose e do VEGF e, portanto, em um ambiente no qual as células já se encontram em processo de regressão.

Esses resultados sugerem que, em contraste com as condições de cultivo na qual houve um estímulo hipóxico constante e homogêneo, no modelo ex vivo e, provavelmente, in vivo, respostas locais como mudanças no fluxo sanguíneo, a disponibilidade de glicose e diferenças no consumo de oxigênio devem afetar as concentrações de oxigênio e assim a resposta celular. No contexto do corpo lúteo canino, o HIF1A parece atuar como fator prósobrevivência regulando a função do corpo lúteo canino no sentido de manter a sua vida útil. 
CONCLUSÃO 


\section{CONCLUSÃO}

Diante do exposto, conclui-se que:

1. A expressão gênica e protéica do HIF1A no corpo lúteo canino aponta para a existência de hipóxia em determinadas fases do diestro.

2. A inter-relação entre a expressão gênica de $H I F 1 A$, o sistema VEGF e os transportadores de glicose $S L C 2 A 1$ e $S L C 2 A 4$, bem como a produção de progesterona, indicam que a hipóxia pode ser um fator crítico para o desenvolvimento e função do corpo lúteo nessa espécie, regulando processos importantes como a angiogênese, a captação de glicose e a esteroidogênese, especialmente na primeira metade do diestro, atuando como fator luteotrófico.

3. A expressão protéica e gênica do GLUT4/SLC2A4 aponta para uma possível participação da insulina na regulação da função do corpo lúteo canino.

4. Por fim, a resposta in vitro difere do que é observado no modelo ex vivo, pois a perda da modulação tecidual coloca a hipóxia como um fator que inibe inibição da produção de esteróides na célula luteínica. 


\section{REFERÊNCIAS}

ACOSTA, T. J.; YOSHIZAWA, N.; OHTANI, M.; MIYAMOTO, A. Local changes in blood flow within the early and midcycle corpus luteum after prostaglandin $\mathrm{F}(2$ alpha) injection in the cow. Biol Reprod, v. 66, n. 3, p. 651-658, 2002.

ANDRAWEERA, P. H.; DEKKER, G. A.; LAURENCE, J. A.; ROBERTS, C. T. Placental expression of VEGF family mRNA in adverse pregnancy outcomes. Placenta, v. 33, n. 6, p. 467-472, 2012.

BARBONI, B.; TURRIANI, M.; GALEATI, G.; SPINACI, M.; BACCI, M. L.; FORNI, M.; MATTIOLI, M. Vascular endothelial growth factor production in growing pig antral follicles. Biol Reprod, v. 63, n. 3, p. 858-864, 2000.

BARROS, R. P.; MACHADO, U. F.; WARNER, M.; GUSTAFSSON, J. A. Muscle GLUT4 regulation by estrogen receptors ERbeta and ERalpha. Proc Natl Acad Sci U S A, v. 103, n. 5, p. 1605-1608, 2006.

BATISTA, M. R.; SMITH, M. S.; SNEAD, W. L.; CONNOLLY, C. C.; LACY, D. B.; MOORE, M. C. Chronic estradiol and progesterone treatment in conscious dogs: effects on insulin sensitivity and response to hypoglycemia. Am J Physiol Regul Integr Comp Physiol, v. 289, n. 4, p. R1064-1073, 2005.

BEHROOZ, A.; ISMAIL-BEIGI, F. Stimulation of Glucose Transport by Hypoxia: Signals and Mechanisms. News Physiol Sci, v. 14, n., p. 105-110, 1999.

BERG, J. M.; TYMOCZKO, J. L.; STRYER, L. Glycolysis and Gluconeogenesis. Nova York: W.H. Freeman and Company, 2002

BHATTI, S. Pituitary and mammary growth hormone in dogs. Ghent University, 2006. 175-201 p.

BISWAS, D. K.; SINGH, S.; SHI, Q.; PARDEE, A. B.; IGLEHART, J. D. Crossroads of estrogen receptor and NF-kappaB signaling. Sci STKE, v. 2005, n. 288, p. pe27, 2005.

BRADFORD, M. M. A rapid and sensitive method for the quantitation of microgram quantities of protein utilizing the principle of protein-dye binding. Anal Biochem, v. 72, n., p. 248-254, 1976.

BROWN, G. K. Glucose transporters: structure, function and consequences of deficiency. $\mathbf{J}$ Inherit Metab Dis, v. 23, n. 3, p. 237-246, 2000.

CAO, Y.; LINDEN, P.; SHIMA, D.; BROWNE, F.; FOLKMAN, J. In vivo angiogenic activity and hypoxia induction of heterodimers of placenta growth factor/vascular endothelial growth factor. J Clin Invest, v. 98, n. 11, p. 2507-2511, 1996.

CELIK-OZENCI, C.; AKKOYUNLU, G.; KAYISLI, U. A.; ARICI, A.; DEMIR, R. Localization of vascular endothelial growth factor in the zona pellucida of developing ovarian follicles in the rat: a possible role in destiny of follicles. Histochem Cell Biol, v. 120, n. 5, p. 383-390, 2003. 
CHANDEL, N. S.; MALTEPE, E.; GOLDWASSER, E.; MATHIEU, C. E.; SIMON, M. C.; SCHUMACKER, P. T. Mitochondrial reactive oxygen species trigger hypoxia-induced transcription. Proc Natl Acad Sci U S A, v. 95, n. 20, p. 11715-11720, 1998.

CHASE, C. C.; DEL VECCHIO, R. P.; SMITH, S. B.; RANDEL, R. D. In vitro metabolism of glucose by bovine reproductive tissues obtained during the estrous cycle and after calving. J Anim Sci, v. 70, n. 5, p. 1496-1508, 1992.

CONCANNON, P. W. Endocrinologic control of normal canine ovarian function. Reprod Domest Anim, v. 44 Suppl 2, n., p. 3-15, 2009.

CONCANNON, P. W. Reproductive cycles of the domestic bitch. Anim Reprod Sci, v. 124, n. 3-4, p. 200-210, 2011.

DENKO, N. C. Hypoxia, HIF1 and glucose metabolism in the solid tumour. Nat Rev Cancer, v. 8 , n. 9 , p. 705-713, 2008.

DEVOTO, L.; KOHEN, P.; VEGA, M.; CASTRO, O.; GONZÁLEZ, R. R.; RETAMALES, I.; CARVALLO, P.; CHRISTENSON, L. K.; STRAUSS, J. F. Control of human luteal steroidogenesis. Mol Cell Endocrinol, v. 186, n. 2, p. 137-141, 2002.

ECKEL, R. H.; GRUNDY, S. M.; ZIMMET, P. Z. The metabolic syndrome. Lancet, v. 365, n. 9468, p. 1415-1428, 2005.

EIGENMANN, J. E.; EIGENMANN, R. Y.; RIJNBERK, A.; VAN DER GAAG, I.; ZAPF, J.; FROESCH, E. R. Progesterone-controlled growth hormone overproduc tion and naturally occurring canine diabetes and acromegaly. Acta Endocrinol (Copenh), v. 104, n. 2, p. 167176, 1983.

EL MESSARI, S.; LELOUP, C.; QUIGNON, M.; BRISORGUEIL, M. J.; PENICAUD, L.; ARLUISON, M. Immunocytochemical localization of the insulin-responsive glucose transporter 4 (Glut4) in the rat central nervous system. J Comp Neurol, v. 399, n. 4, p. 492$512,1998$.

ENGEL, E.; KLEIN, R.; BAUMGÄRTNER, W.; HOFFMANN, B. Investigations on the expression of cytokines in the canine corpus luteum in relation to dioestrus. Anim Reprod Sci, v. 87, n. 1-2, p. 163-176, 2005.

FELDMAN, E. C.; NELSON, R. W. Canine and feline endocrinologyand reproduction: WB Saunders, 2004

FERNANDES, P. A.; BOWEN, R. A.; KOSTAS, A. C.; SAWYER, H. R.; NETT, T. M.; OLSON, P. N. Luteal function in the bitch: changes during diestrus in pituitary concentration of and the number of luteal receptors for luteinizing hormone and prolactin. Biol Reprod, v. 37, n. 4, p. 804-811, 1987.

FIRTH, J. D.; EBERT, B. L.; PUGH, C. W.; RATCLIFFE, P. J. Oxygen-regulated control elements in the phosphoglycerate kinase 1 and lactate dehydrogenase A genes: similarities with the erythropoietin 3' enhancer. Proc Natl Acad Sci U S A, v. 91, n. 14, p. 6496-6500, 1994. 
FROLOVA, A.; FLESSNER, L.; CHI, M.; KIM, S. T.; FOYOUZI-YOUSEFI, N.; MOLEY, K. H. Facilitative glucose transporter type 1 is differentially regulated by progesterone and estrogen in murine and human endometrial stromal cells. Endocrinology, v. 150, n. 3, p. 1512-1520, 2009.

GALIEN, R.; GARCIA, T. Estrogen receptor impairs interleukin-6 expression by preventing protein binding on the NF-kappaB site. Nucleic Acids Res, v. 25, n. 12, p. 2424-2429, 1997.

GOULD, G. W.; HOLMAN, G. D. The glucose transporter family: structure, function and tissue-specific expression. Biochem J, v. 295 ( Pt 2), n., p. 329-341, 1993.

GRASSELLI, F.; BASINI, G.; BUSSOLATI, S.; BIANCO, F. Cobalt chloride, a hypoxiamimicking agent, modulates redox status and functional parameters of cultured swine granulosa cells. Reprod Fertil Dev, v. 17, n. 7, p. 715-720, 2005.

GUZELOGLU-KAYISLI, O.; HALIS, G.; TASKIRAN, S.; KAYISLI, U. A.; ARICI, A. DNA-binding ability of NF-kappaB is affected differently by ERalpha and ERbeta and its activation results in inhibition of estrogen responsiveness. Reprod Sci, v. 15, n. 5, p. 493-505, 2008.

HAHN, T.; DESOYE, G. Ontogeny of glucose transport systems in the placenta and its progenitor tissues. Early Pregnancy, v. 2, n. 3, p. 168-182, 1996.

HARATA, T.; ANDO, H.; IWASE, A.; NAGASAKA, T.; MIZUTANI, S.; KIKKAWA, F. Localization of angiotensin II, the AT1 receptor, angiotensin-converting enzyme, aminopeptidase A, adipocyte-derived leucine aminopeptidase, and vascular endothelial growth factor in the human ovary throughout the menstrual cycle. Fertil Steril, v. 86, n. 2, p. 433-439, 2006.

HAYASHI, M.; SAKATA, M.; TAKEDA, T.; YAMAMOTO, T.; OKAMOTO, Y.; SAWADA, K.; KIMURA, A.; MINEKAWA, R.; TAHARA, M.; TASAKA, K.; MURATA, Y. Induction of glucose transporter 1 expression through hypoxia-inducible factor 1alpha under hypoxic conditions in trophoblast-derived cells. J Endocrinol, v. 183, n. 1, p. 145-154, 2004.

HEIKKILÄ, M.; PASANEN, A.; KIVIRIKKO, K. I.; MYLLYHARJU, J. Roles of the human hypoxia-inducible factor (HIF)-3a variants in the hypoxia response. Cell Mol Life Sci, v. 68, n. 23, p. 3885-3901, 2011.

HOFFMANN, B.; HÖVELER, R.; HASAN, S. H.; FAILING, K. Ovarian and pituitary function in dogs after hysterectomy. J Reprod Fertil, v. 96, n. 2, p. 837-845, 1992.

HOFFMANN, B.; RIESENBECK, A.; SCHAMS, B.; STEINETZ, B. G. Aspects on Hormonal Control of Normal and Induced Parturition in the Dog. Reprod Dom Anim, v. 34, n., p. 7, 1999.

HOFFMANN, B.; BÜSGES, F.; ENGEL, E.; KOWALEWSKI, M. P.; PAPA, P. Regulation of corpus luteum-function in the bitch. Reprod Domest Anim, v. 39, n. 4, p. 232-240, 2004. 
HOFFMANN, B.; BÜSGES, F.; BAUMGÄRTNER, W. Immunohistochemical detection of CD4-, CD8- and MHC II-expressing immune cells and endoglin in the canine corpus luteum at different stages of dioestrus. Reprod Domest Anim, v. 39, n. 6, p. 391-395, 2004.

IVAN, M.; KONDO, K.; YANG, H.; KIM, W.; VALIANDO, J.; OHH, M.; SALIC, A.; ASARA, J. M.; LANE, W. S.; KAELIN, W. G. HIFalpha targeted for VHL-mediated destruction by proline hydroxylation: implications for O2 sensing. Science, v. 292, n. 5516, p. 464-468, 2001.

JAAKKOLA, P.; MOLE, D. R.; TIAN, Y. M.; WILSON, M. I.; GIELBERT, J.; GASKELL, S. J.; KRIEGSHEIM AV; HEBESTREIT, H. F.; MUKHERJI, M.; SCHOFIELD, C. J.; MAXWELL, P. H.; PUGH, C. W.; RATCLIFFE, P. J. Targeting of HIF-alpha to the von Hippel-Lindau ubiquitylation complex by O2-regulated prolyl hydroxylation. Science, v. 292, n. 5516, p. 468-472, 2001.

JEWELL, U. R.; KVIETIKOVA, I.; SCHEID, A.; BAUER, C.; WENGER, R. H.; GASSMANN, M. Induction of HIF-1alpha in response to hypoxia is instantaneous. FASEB J, v. 15, n. 7, p. 1312-1314, 2001.

JIANG, B. H.; SEMENZA, G. L.; BAUER, C.; MARTI, H. H. Hypoxia-inducible factor 1 levels vary exponentially over a physiologically relevant range of $\mathrm{O} 2$ tension. Am J Physiol, v. 271, n. 4 Pt 1, p. C1172-1180, 1996.

JIANG, Y. F.; TSUI, K. H.; WANG, P. H.; LIN, C. W.; WANG, J. Y.; HSU, M. C.; CHEN, Y. C.; CHIU, C. H. Hypoxia regulates cell proliferation and steroidogenesis through protein kinase A signaling in bovine corpus luteum. Anim Reprod Sci, v. 129, n. 3-4, p. 152-161, 2011.

JOHNSON, C. A. Glucose homeostasis during canine pregnancy: Insulin resistance, ketosis, and hypoglycemia. Theriogenology, v. 70, n. 9, p. 1418-1423, 2008.

JOOST, H. G.; BELL, G. I.; BEST, J. D.; BIRNBAUM, M. J.; CHARRON, M. J.; CHEN, Y. T.; DOEGE, H.; JAMES, D. E.; LODISH, H. F.; MOLEY, K. H.; MOLEY, J. F.; MUECKLER, M.; ROGERS, S.; SCHÜRMANN, A.; SEINO, S.; THORENS, B. Nomenclature of the GLUT/SLC2A family of sugar/polyol transport facilitators. Am J Physiol Endocrinol Metab, v. 282, n. 4, p. E974-976, 2002.

JOSKO, J.; GWÓZDZ, B.; JEDRZEJOWSKA-SZYPULKA, H.; HENDRYK, S. Vascular endothelial growth factor (VEGF) and its effect on angiogenesis. Med Sci Monit, v. 6, n. 5, p. 1047-1052, 2000.

KAAJA, R. J.; GREER, I. A. Manifestations of chronic disease during pregnancy. JAMA, v. 294, n. 21, p. 2751-2757, 2005.

KIM, S. T.; MOLEY, K. H. Regulation of facilitative glucose transporters and AKT/MAPK/PRKAA signaling via estradiol and progesterone in the mouse uterine epithelium. Biol Reprod, v. 81, n. 1, p. 188-198, 2009. 
KODAMAN, P. H.; BEHRMAN, H. R. Hormone-regulated and glucose-sensitive transport of dehydroascorbic acid in immature rat granulosa cells. Endocrinology, v. 140, n. 8, p. 36593665, 1999.

KOGA, K.; OSUGA, Y.; TSUTSUMI, O.; MOMOEDA, M.; SUENAGA, A.; KUGU, K.; FUJIWARA, T.; TAKAI, Y.; YANO, T.; TAKETANI, Y. Evidence for the presence of angiogenin in human follicular fluid and the up-regulation of its production by human chorionic gonadotropin and hypoxia. J Clin Endocrinol Metab, v. 85, n. 9, p. 3352-3355, 2000.

KOGIKA, M. M.; BRANDÃO, L. P.; JERICÓ, M. M.; HAGIWARA, M. K.; SIMÕES, D. M. N.; MENDONÇA, B. DETERMINAÇÃO DAS CONCENTRAÇÕES SÉRICAS DE GLICOSE

E INSULINA DE CÃES EM CHOQUE ENDOTÓXICO. Ciência Rural, v. 31, n. 5, p. 4, 2001.

KOL, S.; BEN-SHLOMO, I.; RUUTIAINEN, K.; ANDO, M.; DAVIES-HILL, T. M.;

ROHAN, R. M.; SIMPSON, I. A.; ADASHI, E. Y. The midcycle increase in ovarian glucose uptake is associated with enhanced expression of glucose transporter 3. Possible role for interleukin-1, a putative intermediary in the ovulatory process. J Clin Invest, v. 99, n. 9, p. 2274-2283, 1997.

KOWALEWSKI, M.; MASON, J.; HOWIE, A.; MORLEY, S.; SCHULER, G.;

HOFFMANN, B. Characterization of the canine 3beta-hydroxysteroid dehydrogenase and its expression in the corpus luteum during diestrus. J Steroid Biochem Mol Biol, v. 101, n. 4-5, p. 254-262, 2006a.

KOWALEWSKI, M.; SCHULER, G.; TAUBERT, A.; ENGEL, E.; HOFFMANN, B. Expression of cyclooxygenase 1 and 2 in the canine corpus luteum during diestrus. Theriogenology, v. 66, n. 6-7, p. 1423-1430, 2006b.

KOWALEWSKI, M.; MUTEMBEI, H.; HOFFMANN, B. Canine prostaglandin F2alpha receptor (FP) and prostaglandin F2alpha synthase (PGFS): molecular cloning and expression in the corpus luteum. Anim Reprod Sci, v. 107, n. 1-2, p. 161-175, 2008.

KOWALEWSKI, M.; HOFFMANN, B. Molecular cloning and expression of StAR protein in the canine corpus luteum during dioestrus. Exp Clin Endocrinol Diabetes, v. 116, n. 3, p. 158-161, 2008.

LEVY, A. P.; LEVY, N. S.; GOLDBERG, M. A. Post-transcriptional regulation of vascular endothelial growth factor by hypoxia. J Biol Chem, v. 271, n. 5, p. 2746-2753, 1996.

LEVY, J. C.; MATTHEWS, D. R.; HERMANS, M. P. Correct homeostasis model assessment (HOMA) evaluation uses the computer program. Diabetes Care, v. 21, n. 12, p. 2191-2192, 1998.

LIVINGSTONE, C.; LYALL, H.; GOULD, G. W. Hypothalamic GLUT 4 expression: a glucose- and insulin-sensing mechanism? Mol Cell Endocrinol, v. 107, n. 1, p. 67-70, 1995. 
LUZ, M.; BERTAN, C.; BINELLI, M.; LOPES, M. In vitro PGF2alpha production by endometrium and corpus luteum explants from pregnant and nonpregnant diestrus bitches and placental explants from pregnant bitches. Theriogenology, v. 66, n. 6-7, p. 1442-1447, 2006a.

LUZ, M.; CESÁRIO, M.; BINELLI, M.; LOPES, M. Canine corpus luteum regression: apoptosis and caspase-3 activity. Theriogenology, v. 66, n. 6-7, p. 1448-1453, 2006b.

MARIANI, T.; DO PRADO, C.; SILVA, L.; PAARMANN, F.; LIMA, M.; CARVALHO, I.; CAMPOS, D.; ARTONI, L.; HERNANDEZ-BLAZQUEZ, F.; PAPA, P. Immunohistochemical localization of VEGF and its receptors in the corpus luteum of the bitch during diestrus and anestrus. Theriogenology, v. 66, n. 6-7, p. 1715-1720, 2006.

MARTI, H. H. Angiogenesis--a self-adapting principle in hypoxia. EXS, v., n. 94, p. 163-180, 2005.

MATTHEWS, D. R.; HOSKER, J. P.; RUDENSKI, A. S.; NAYLOR, B. A.; TREACHER, D. F.; TURNER, R. C. Homeostasis model assessment: insulin resistance and beta-cell function from fasting plasma glucose and insulin concentrations in man. Diabetologia, v. 28, n. 7, p. 412-419, 1985.

MAXWELL, P. H.; PUGH, C. W.; RATCLIFFE, P. J. Inducible operation of the erythropoietin 3' enhancer in multiple cell lines: evidence for a widespread oxygen-sensing mechanism. Proc Natl Acad Sci U S A, v. 90, n. 6, p. 2423-2427, 1993.

MAXWELL, P. H.; WIESENER, M. S.; CHANG, G. W.; CLIFFORD, S. C.; VAUX, E. C.; COCKMAN, M. E.; WYKOFF, C. C.; PUGH, C. W.; MAHER, E. R.; RATCLIFFE, P. J. The tumour suppressor protein VHL targets hypoxia-inducible factors for oxygen-dependent proteolysis. Nature, v. 399, n. 6733, p. 271-275, 1999.

MAXWELL, P. H.; PUGH, C. W.; RATCLIFFE, P. J. Activation of the HIF pathway in cancer. Curr Opin Genet Dev, v. 11, n. 3, p. 293-299, 2001.

MUECKLER, M. Family of glucose-transporter genes. Implications for glucose homeostasis and diabetes. Diabetes, v. 39, n. 1, p. 6-11, 1990.

NANGAKU, M.; ECKARDT, K. U. Hypoxia and the HIF system in kidney disease. J Mol Med (Berl), v. 85, n. 12, p. 1325-1330, 2007.

NEUFELD, G.; COHEN, T.; GENGRINOVITCH, S.; POLTORAK, Z. Vascular endothelial growth factor (VEGF) and its receptors. FASEB J, v. 13, n. 1, p. 9-22, 1999.

NGUYEN, S. V.; CLAYCOMB, W. C. Hypoxia regulates the expression of the adrenomedullin and HIF-1 genes in cultured HL-1 cardiomyocytes. Biochem Biophys Res Commun, v. 265, n. 2, p. 382-386, 1999.

NILSSON, S.; MÄKELÄ, S.; TREUTER, E.; TUJAGUE, M.; THOMSEN, J.; ANDERSSON, G.; ENMARK, E.; PETTERSSON, K.; WARNER, M.; GUSTAFSSON, J. A. Mechanisms of estrogen action. Physiol Rev, v. 81, n. 4, p. 1535-1565, 2001. 
NISHIMOTO, H.; MATSUTANI, R.; YAMAMOTO, S.; TAKAHASHI, T.; HAYASHI, K. G.; MIYAMOTO, A.; HAMANO, S.; TETSUKA, M. Gene expression of glucose transporter (GLUT) 1, 3 and 4 in bovine follicle and corpus luteum. J Endocrinol, v. 188, n. 1, p. 111$119,2006$.

NISHIMURA, R.; SAKUMOTO, R.; TATSUKAWA, Y.; ACOSTA, T. J.; OKUDA, K. Oxygen concentration is an important factor for modulating progesterone synthesis in bovine corpus luteum. Endocrinology, v. 147, n. 9, p. 4273-4280, 2006.

NISHIMURA, R.; KOMIYAMA, J.; TASAKI, Y.; ACOSTA, T. J.; OKUDA, K. Hypoxia promotes luteal cell death in bovine corpus luteum. Biol Reprod, v. 78, n. 3, p. 529-536, 2008.

NISHIMURA, R.; OKUDA, K. Hypoxia is important for establishing vascularization during corpus luteum formation in cattle. J Reprod Dev, v. 56, n. 1, p. 110-116, 2010.

OHH, M.; PARK, C. W.; IVAN, M.; HOFFMAN, M. A.; KIM, T. Y.; HUANG, L. E.; PAVLETICH, N.; CHAU, V.; KAELIN, W. G. Ubiquitination of hypoxia-inducible factor requires direct binding to the beta-domain of the von Hippel-Lindau protein. Nat Cell Biol, v. 2, n. 7, p. 423-427, 2000.

OKUNO, S.; AKAZAWA, S.; YASUHI, I.; KAWASAKI, E.; MATSUMOTO, K.; YAMASAKI, H.; MATSUO, H.; YAMAGUCHI, Y.; NAGATAKI, S. Decreased expression of the GLUT4 glucose transporter protein in adipose tissue during pregnancy. Horm Metab Res, v. 27, n. 5, p. 231-234, 1995.

OTANI, N.; MINAMI, S.; YAMOTO, M.; SHIKONE, T.; OTANI, H.; NISHIYAMA, R.; OTANI, T.; NAKANO, R. The vascular endothelial growth factor/fms-like tyrosine kinase system in human ovary during the menstrual cycle and early pregnancy. J Clin Endocrinol Metab, v. 84, n. 10, p. 3845-3851, 1999.

PALMER, L. A.; SEMENZA, G. L.; STOLER, M. H.; JOHNS, R. A. Hypoxia induces type II NOS gene expression in pulmonary artery endothelial cells via HIF-1. Am J Physiol, v. 274, n. 2 Pt 1, p. L212-219, 1998.

PAPA, P. C.; HOFFMANN, B. The corpus luteum of the dog: source and target of steroid hormones? Reprod Domest Anim, v. 46, n. 4, p. 750-756, 2011.

PFARRER, C. D.; RUZIWA, S. D.; WINTHER, H.; CALLESEN, H.; LEISER, R.;

SCHAMS, D.; DANTZER, V. Localization of vascular endothelial growth factor (VEGF) and its receptors VEGFR-1 and VEGFR-2 in bovine placentomes from implantation until term.

Placenta, v. 27, n. 8, p. 889-898, 2006.

PÖPPL, A. G.; LASTA, C. S.; GONZÁLEZ, F. H. D.; KUCHARSKI, L. C.; SILVA, R. S. M. Insulin sensitivity indexes in female dogs:effect of estrus cycle and pyometra. Acta Scientiae Veterinariae, v. 37, n. 4, p. 9, 2009.

QIU, Y.; SEAGER, M.; OSMAN, A.; CASTLE-MILLER, J.; BEVAN, H.; TORTONESE, D. J.; MURPHY, D.; HARPER, S. J.; FRASER, H. M.; DONALDSON, L. F.; BATES, D. O. 
Ovarian VEGF(165)b expression regulates follicular development, corpus luteum function and fertility. Reproduction, v. 143, n. 4, p. 501-511, 2012.

QUINTANA, R.; KOPCOW, L.; SUELDO, C.; MARCONI, G.; RUEDA, N. G.;

BARAÑAO, R. I. Direct injection of vascular endothelial growth factor into the ovary of mice promotes follicular development. Fertil Steril, v. 82 Suppl 3, n., p. 1101-1105, 2004.

RABIEE, A. R.; LEAN, I. J.; GOODEN, J. M.; MILLER, B. G.; SCARAMUZZI, R. J. An evaluation of transovarian uptake of metabolites using arterio-venous difference methods in dairy cattle. Anim Reprod Sci, v. 48, n. 1, p. 9-25, 1997.

REA, S.; JAMES, D. E. Moving GLUT4: the biogenesis and trafficking of GLUT4 storage vesicles. Diabetes, v. 46, n. 11, p. 1667-1677, 1997.

ROBERTS, A. E.; ARBOGAST, L. K.; FRIEDMAN, C. I.; COHN, D. E.; KAUMAYA, P. T.; DANFORTH, D. R. Neutralization of endogenous vascular endothelial growth factor depletes primordial follicles in the mouse ovary. Biol Reprod, v. 76, n. 2, p. 218-223, 2007.

ROYER, C.; LACHUER, J.; CROUZOULON, G.; ROUX, J.; PEYRONNET, J.; MAMET, J.; PEQUIGNOT, J.; DALMAZ, Y. Effects of gestational hypoxia on mRNA levels of Glut3 and Glut4 transporters, hypoxia inducible factor- 1 and thyroid hormone receptors in developing rat brain. Brain Res, v. 856, n. 1-2, p. 119-128, 2000.

RUAN, H.; HACOHEN, N.; GOLUB, T. R.; VAN PARIJS, L.; LODISH, H. F. Tumor necrosis factor-alpha suppresses adipocyte-specific genes and activates expression of preadipocyte genes in 3T3-L1 adipocytes: nuclear factor-kappaB activation by TNF-alpha is obligatory. Diabetes, v. 51, n. 5, p. 1319-1336, 2002.

SEMENZA, G. L.; JIANG, B. H.; LEUNG, S. W.; PASSANTINO, R.; CONCORDET, J. P.; MAIRE, P.; GIALLONGO, A. Hypoxia response elements in the aldolase A, enolase 1, and lactate dehydrogenase A gene promoters contain essential binding sites for hypoxia-inducible factor 1. J Biol Chem, v. 271, n. 51, p. 32529-32537, 1996.

SEMENZA, G. L. Targeting HIF-1 for cancer therapy. Nat Rev Cancer, v. 3, n. 10, p. 721$732,2003$.

SILVA, J. L.; GIANNOCCO, G.; FURUYA, D. T.; LIMA, G. A.; MORAES, P. A.;

NACHEF, S.; BORDIN, S.; BRITTO, L. R.; NUNES, M. T.; MACHADO, U. F. NF-kappaB, MEF2A, MEF2D and HIF1-a involvement on insulin- and contraction-induced regulation of GLUT4 gene expression in soleus muscle. Mol Cell Endocrinol, v. 240, n. 1-2, p. 82-93, 2005.

SILVA, R. S. Insulina e captação de glicose em corpo lúteo canino. Faculdade de Medicina Veterinária e Zootecnia da Universidade de São Paulo, 2012. 101 p.

SIMARD, J.; RICKETTS, M. L.; GINGRAS, S.; SOUCY, P.; FELTUS, F. A.; MELNER, M. $\mathrm{H}$. Molecular biology of the 3beta-hydroxysteroid dehydrogenase/delta5-delta4 isomerase gene family. Endocr Rev, v. 26, n. 4, p. 525-582, 2005. 
SOLOMON, C. G.; HU, F. B.; DUNAIF, A.; RICH-EDWARDS, J.; WILLETT, W. C.; HUNTER, D. J.; COLDITZ, G. A.; SPEIZER, F. E.; MANSON, J. E. Long or highly irregular menstrual cycles as a marker for risk of type 2 diabetes mellitus. JAMA, v. 286, n. 19, p. 2421-2426, 2001.

SONNACK, M. Untersuchungen zur Bildung, regression and Funktionalitat des Corpus Luteum der nicht graviden Hundin, morphologische and biochemische Aspeckte., Justus-Liebig-Universitat Giessen, 2009.

STOCCO, D. M. StAR protein and the regulation of steroid hormone biosynthesis. Annu Rev Physiol, v. 63, n., p. 193-213, 2001.

STROKA, D. M.; BURKHARDT, T.; DESBAILLETS, I.; WENGER, R. H.; NEIL, D. A.; BAUER, C.; GASSMANN, M.; CANDINAS, D. HIF-1 is expressed in normoxic tissue and displays an organ-specific regulation under systemic hypoxia. FASEB J, v. 15, n. 13, p. 2445-2453, 2001.

THORENS, B.; MUECKLER, M. Glucose transporters in the 21st Century. Am J Physiol Endocrinol Metab, v. 298, n. 2, p. E141-145, 2010.

VERKEST, K. R.; FLEEMAN, L. M.; RAND, J. S.; MORTON, J. M. Basal measures of insulin sensitivity and insulin secretion and simplified glucose tolerance tests in dogs. Domest Anim Endocrinol, v. 39, n. 3, p. 194-204, 2010.

VON WOLFF, M.; URSEL, S.; HAHN, U.; STELDINGER, R.; STROWITZKI, T. Glucose transporter proteins (GLUT) in human endometrium: expression, regulation, and function throughout the menstrual cycle and in early pregnancy. J Clin Endocrinol Metab, v. 88, n. 8, p. 3885-3892, 2003.

WEIDEMANN, A.; JOHNSON, R. S. Biology of HIF-1alpha. Cell Death Differ, v. 15, n. 4, p. 621-627, 2008.

WENGER, R. H. Cellular adaptation to hypoxia: O2-sensing protein hydroxylases, hypoxiainducible transcription factors, and O2-regulated gene expression. FASEB J, v. 16, n. 10, p. 1151-1162, 2002.

WILLIAMS, S. A.; BLACHE, D.; MARTIN, G. B.; FOOT, R.; BLACKBERRY, M. A.; SCARAMUZZI, R. J. Effect of nutritional supplementation on quantities of glucose transporters 1 and 4 in sheep granulosa and theca cells. Reproduction, v. 122, n. 6, p. 947956, 2001.

WINNETT, G.; VAN HAGEN, D.; SCHREY, M. Prostaglandin J2 metabolites inhibit aromatase activity by redox-sensitive mechanisms: potential implications for breast cancer therapy. Int J Cancer, v. 103, n. 5, p. 600-605, 2003.

YANG, H.; LEE, H. H.; LEE, H. C.; KO, D. S.; KIM, S. S. Assessment of vascular endothelial growth factor expression and apoptosis in the ovarian graft: can exogenous gonadotropin promote angiogenesis after ovarian transplantation? Fertil Steril, v. 90, n. 4 Suppl, p. 1550-1558, 2008. 
YOUNG, L. H.; RENFU, Y.; RUSSELL, R.; HU, X.; CAPLAN, M.; REN, J.; SHULMAN, G. I.; SINUSAS, A. J. Low-flow ischemia leads to translocation of canine heart GLUT-4 and GLUT-1 glucose transporters to the sarcolemma in vivo. Circulation, v. 95, n. 2, p. 415-422, 1997.

ZHANG, J. Z.; BEHROOZ, A.; ISMAIL-BEIGI, F. Regulation of glucose transport by hypoxia. Am J Kidney Dis, v. 34, n. 1, p. 189-202, 1999.

ZHANG, Z.; YIN, D.; WANG, Z. Contribution of hypoxia-inducible factor-1a to transcriptional regulation of vascular endothelial growth factor in bovine developing luteal cells. Anim Sci J, v. 82, n. 2, p. 244-250, 2011.

ZHOU, J.; BIEVRE, M.; BONDY, C. A. Reduced GLUT1 expression in Igf1-/- null oocytes and follicles. Growth Horm IGF Res, v. 10, n. 3, p. 111-117, 2000.

ZHOU, L.; CHEN, H.; XU, P.; CONG, L. N.; SCIACCHITANO, S.; LI, Y.; GRAHAM, D.; JACOBS, A. R.; TAYLOR, S. I.; QUON, M. J. Action of insulin receptor substrate-3 (IRS-3) and IRS-4 to stimulate translocation of GLUT4 in rat adipose cells. Mol Endocrinol, v. 13, n. 3, p. 505-514, 1999. 